\title{
HnRNP L binds a cis-acting RNA sequence element that enables intron-independent gene expression
}

\author{
Xuedong Liu ${ }^{1,2}$ and Janet E. Mertz ${ }^{1,3}$ \\ ${ }^{1}$ McArdle Laboratory for Cancer Research and ${ }^{2}$ Laboratory of Genetics, University of Wisconsin, Madison, Wisconsin \\ 53706-1559 USA
}

\begin{abstract}
Most pre-mRNAs require an intron for efficient processing in higher eukaryotes. To test the hypothesis that intron-independent gene expression involves positive, cis-acting RNA sequence elements, we constructed chimeric genes in which various regions of the naturally intronless HSV-TK gene were inserted into an intronless variant of the highly intron-dependent human $\beta$-globin gene. Using a transient transfection assay, we identified a 119-nucleotide sequence element contained within the transcribed region of the HSV-TK gene that enables efficient cytoplasmic accumulation of globin RNA in the absence of splicing. RNA UV-cross-linking assays indicated that a $68-\mathrm{kD}$ protein present in nuclear extracts of HeLa and COS cells specifically binds to this HSV-TK sequence element. This 68-kD protein was found to cross-react with an antiserum specific to hnRNP L. Recombinant hnRNP L was shown to bind with high sequence specificity to this RNA sequence element. Analysis of substitution mutants in this element indicated that binding of hnRNP $L$ correlates with accumulation of the RNA in the cytoplasm. Thus, we conclude that (1) hnRNP L binds in a sequence-specific manner to this RNA sequence element that enables intron-independent gene expression, and (2) intron-independent pre-mRNA processing and transport involves sequence-specific RNA-protein interactions between cis-acting RNA sequence elements and proteins such as hnRNP L. This sequence element may be of general use for the efficient expression of cDNA versions of intron-dependent genes.
\end{abstract}

[Key Words: $\beta$-Globin; herpes simplex virus thymidine kinase gene; intron requirement; pre-mRNA processing enhancer (PPE); RNA transport]

Received April 18, 1995; revised version accepted June 6, 1995.

Formation of mature mRNAs in higher eukaryotes requires several processing steps in the nucleus prior to transport to the cytoplasm. For intron-containing transcripts, these steps include $5^{\prime}$-cap formation, methylation, 3 '-end cleavage and polyadenylation, and splicing. Intronless transcripts do not undergo splicing but, in most cases, still need to undergo these other steps in pre-mRNA processing. Much information has been obtained concerning the biochemistry and machinery involved in these nuclear processing events (for review, see Green 1991). Nevertheless, their relationship to nuclear export and cytoplasmic accumulation remains poorly understood.

The first evidence linking splicing and the accumulation of mRNA in the cytoplasm came from studies with SV40 (Gruss et al. 1979). Cells transfected with SV40 mutants lacking an excisable intron in the late region of the viral genome were found to synthesize SV40 late transcripts but not to accumulate SV40 late mRNAs in

\footnotetext{
${ }^{3}$ Corresponding author.
}

the cytoplasm. The requirement of an intron for efficient cytoplasmic accumulation of mRNA (i.e., intron-dependent gene expression) has been subsequently demonstrated for many other genes as well, including those encoding $\beta$-globin (Hamer and Leder 1979; Buchman and Berg 1988; Ryu 1989; Collis et al. 1990), ribosomal protein L32 (Chung and Perry 1989), purine nucleoside phosphorylase (PNP) (Jonsson et al. 1992), immunoglobulin $\mu$ (Neuberger and Williams 1988), mouse thymidylate synthase (Deng et al. 1989), mouse dihydrofolate reductase (DHFR) (Gasser et al. 1982), plant alcohol dehydrogenase-1 (Callis et al. 1987), and triosephosphate isomerase (TPI) (Nesic et al. 1993). It has been proposed that the presence of introns can protect pre-mRNAs from degradation in the nucleus (Hamer and Leder 1979; Buchman and Berg 1988; Ryu and Mertz 1989|, facilitate polyadenylation (Collis et al. 1990; Huang and Gorman 1990; Niwa et al. 1990; Pandey et al. 1990; Nesic et al. 1993; W.-S. Ryu, G.W. Gelembiuk, X. Liu, and J.E. Mertz, in prep.), facilitate excision of an adjacent intron (Ryu 1989; Nesic and Maquat 1994), and target mRNAs for export to the cytoplasm (Hamer and Leder 1979; 
Buchman and Berg 1988; Chang and Sharp 1989; Legrain and Rosbash 1989; Ryu and Mertz 1989).

Nonetheless, the presence of introns in pre-mRNAs is not a universal requirement for proper mRNA biogenesis. The genes encoding herpes simplex virus type 1 thymidine kinase (HSV-TK) (McKnight 1980), histone proteins (Kedes 1979), $\alpha$-interferon (Nagata et al. 1980), $\beta$-adrenergic receptor (Koilka et al. 1987), and c-jun (Hattori et al. 1988) are among those genes discovered to be naturally intronless yet expressed at functional levels in higher eukaryotes.

To begin to understand the mechanism of intron-independent mRNA biogenesis, Greenspan and Weissman (1985), Buchman and Berg (1988), and Ryu (1989) constructed plasmids in which an intron plus some adjacent exon sequence from an intron-requiring $\beta$-globin gene were placed $3^{\prime}$ of the intronless sequence that encodes HSV-TK. Greenspan and Weissman (1985) found that much of the resulting chimeric TK-globin RNA was polyadenylated and transported to the cytoplasm without intron excision. All three laboratories showed that the chimeric RNAs efficiently accumulated in mammalian cells regardless of whether an intron was present in the primary transcript.

One hypothesis to explain these data is that transcripts synthesized from $\beta$-globin and other intron-dependent genes contain negative, cis-acting RNA sequence elements that prevent them from being properly processed and/or transported in the absence of introns; transcripts synthesized from intron-independent genes lack these negative elements and therefore do not require introns for proper processing and transport. During the past decade, considerable data have accumulated in the literature to support this hypothesis. For example, Legrain and Rosbash (1989) found that mutations in splicing signals that converted an intron-containing gene into an intronless one led to efficient cytoplasmic accumulation of the intronless transcripts. Thus, they hypothesized that intronless transcripts are transported to the cytoplasm by default pathways.

An alternative, nonmutually exclusive hypothesis is that transcripts synthesized from intron-independent genes contain positive, cis-acting RNA sequence elements that enable them to be processed and transported regardless of whether or not introns are present. Greenspan and Weissman (1985) and Buchman and Berg (1988) found that various nonoverlapping regions of the HSV-TK gene accumulate in cells in the absence of intron excision. Thus, HSV-TK transcripts are processed and transported to the cytoplasm regardless of introns because they either (1) lack a negative cis-acting element, or (2) contain multiple, positive cis-acting elements.

To test whether transcripts of the HSV-TK gene actually do contain positive cis-acting RNA sequence elements that enable intron-independent pre-mRNA processing and transport in higher eukaryotes, we examined processing and transport in mammalian cells of transcripts synthesized from an intronless variant of the human $\beta$-globin gene containing insertions of various se- quences from the HSV-TK gene. We found that a 119nucleotide sequence contained within the transcribed region of the HSV-TK gene can enable efficient cytoplasmic accumulation of $\beta$-globin transcripts in the absence of splicing. Furthermore, we also found that heterogeneous nuclear ribonucleoprotein L (hnRNP L), an abundant $68-\mathrm{kD}$ cellular protein of previously unknown function, associates sequence specifically with this premRNA processing enhancer (PPE) but not with a mutant variant of it defective in rescuing the cytoplasmic accumulation of intronless human $\beta$-globin transcripts. Thus, intron-independent pre-mRNA processing and transport can involve sequence-specific RNA-protein interactions between PPEs and appropriate cellular factors such as hnRNP L.

\section{Results}

Sequences contained within the transcribed region of the HSV-TK gene enable efficient processing of intronless human $\beta$-globin transcripts

To confirm and extend the preliminary findings of Greenspan and Weissman (1985), Buchman and Berg (1988), and Ryu (1989), we first constructed pTK $\beta 1$ $|-| 2|-|$ and $\operatorname{pTK} \beta 1|+| 2|+|$, plasmids into which the HSV-TK nucleotide residues 59-1238 (relative to the transcription initiation site) (McKnight et al. 1981) were inserted in the sense orientation into a complete cDNA and genomic version, respectively, of the human $\beta$-globin gene (Fig. 1A). The genomic version of the hybrid gene served as a control for message stability in the cytoplasm. Because the mature mRNAs generated from these plasmids are identical in primary structure, they should have identical half-lives in the cytoplasm unless processing via alternative pathways in the nucleus affects the location or association with ribonuclear proteins in the cytoplasm. Therefore, we assumed that the ratio of TK-globin chimeric RNA accumulated in the cytoplasm of cells transfected in parallel with the cDNA relative to the genomic version of a hybrid gene provides a reasonable indication as to the effectiveness of the HSV-TK sequence in allowing intron-independent gene expression.

These plasmids were cotransfected in parallel into monkey cells along with pRSV-Tori, a plasmid encoding the SV40 large T antigen (Ryu 1989; Yu et al. 1991). The presence of the latter plasmid results in replication of the test plasmid to high copy number, making structural and quantitative analysis of the accumulated $\beta$-globin-like RNAs easy to perform by quantitative $S 1$ nuclease mapping techniques (Ryu 1989; Yu et al. 1991; Liu and Mertz 1993). As negative and positive controls, we also transfected in parallel the plasmids $\mathrm{p} \beta|-| 2|-|$ and $\mathrm{p} \beta 1|+| 2|+|$, which contain cDNA and genomic versions of the human $\beta$-globin gene, respectively. The amounts of cytoplasmic and nuclear globin-like RNA accumulated in cells transfected with each plasmid were determined relative to the amounts accumulated in $\mathrm{p} \beta 1|+| 2|+|$-transfected cells $($ Fig. $1 \mathrm{~B}$; summarized in Fig. 1A). 
Figure 1. Presence of HSV-TK sequences in cis can obviate the intron requirement for the processing of human $\beta$-globin transcripts. (A) Structures of plasmids containing an insertion of the transcribed region of the HSV-TK gene into the $5^{\prime}$-untranslated region of the human $\beta$-globin gene, and a summary of the data obtained with them. Only the transcribed region of each gene is shown. The remainder of each plasmid is identical in sequence and described in detail elsewhere (Ryu 1989; Yu et al. 1991). (Shaded boxes) Human $\beta$-globin exon sequences; (open boxes) human $\beta$-globin intron sequences; (hatched boxes) sequences from the transcribed region of the HSV-TK gene. Numbers at the ends of the hatched boxes denote endpoints of the HSV-TK sequence inserted, in nucleotides relative to the HSV-TK gene's transcription initiation site. (B) BamHI; (N) NcoI; (E) EcoRI. The first column on the right indicates the amount of $\beta$-globin-like RNA present in the nucleus of cells transfected with each plasmid, relative to the amount accumulated in cells transfected in parallel with $\mathrm{p} \beta 1|+| 2 \mid+1$. The second column indicates the amount of $\beta$-globinlike RNA accumulated in the cytoplasm of these same cells relative to that accumulated in the $\mathrm{p} \beta 1|+| 2|+|$-transfected cells. The last column on the right indicates the amount of $\beta$-globin-like RNA present in the cytoplasm of cells transfected with the plasmid containing the cDNA version of the gene, relative to the amount accumulated in cells transfected in parallel with the plasmid containing the corresponding genomic version of this gene, with normalization to the relative amounts of $(1)$ cellular $\beta$-actin present in the same RNA samples, and (2) replicated $\beta$-globin-encoding plasmid DNA present in the nuclear samples obtained from these cells (data not shown). These data are means \pm S.E.M. from two experiments and were obtained from gels similar to the one shown in $B$. (B) Autoradiograph of quantitative S1 nuclease mapping analysis of the human $\beta$-globin-like RNAs accumulated in the nucleus and cytoplasm of cells transfected with the plasmids shown in $A$. Each of the globin-encoding plasmids was cotransfected into CV-1PD cells along with the SV40 large T antigen-encoding plasmid pRSV-Tori (Ryu 1989). The nuclear (N) and cytoplasmic (C) RNAs were harvested $48 \mathrm{hr}$ later and analyzed by concurrent S1 nuclease mapping with the $5^{\prime}$-end-labeled globin-and actin-specific probes shown in $C$ and $D$, respectively. The DNA fragments resulting from protection with the globin and actin RNAs are indicated by the arrows. (M) Markers of Mspl-cut pBR322 DNA. (C) Schematic diagram of the human $\beta$-globin probe, described previously (Ryu 1989; Yu et al. 1991), used in the S1 nuclease mapping analysis shown in $B$. The sizes of the DNA fragments resulting from protection by hybridization with the corresponding RNAs are indicated. The human $\beta$-globin probe was 5 '-end-labeled at the $B a m H I$ site; the wavy line indicates the discontinuity between the probe and the globin RNA. Abbreviations are as described in $A$. (D) Schematic diagram of the cellular $\beta$-actin probe, described previously (Ryu 1989; Yu et al. 1991), used as an internal control in the S1 nuclease mapping experiment shown in $B$. The actin probe was $5^{\prime}$-end-labeled at the RsaI site. This probe has pBR322 sequences, indicated by wavy line, adjacent to the Sall site of the $\beta$-actin gene.

As expected, little if any RNA synthesized from the cDNA version of the gene was detectable in the cytoplasm (Fig. 1B, lanes 2,3). On the other hand, RNA synthesized from the genomic version accumulated to high levels (Fig. 1B, lanes 4,5). Insertion of sequences from the HSV-TK gene into the $5^{\prime}$-untranslated region of the human $\beta$-globin cDNA also enabled high-level accumulation of globin-like RNA in the cytoplasm. In sharp contrast to the $>100$-fold difference in cytoplasmic accumulation observed between cells transfected with $\mathrm{p} \beta 1|-| 2|-|$ versus $\mathrm{p} \beta 1|+| 2 \mid+1$, only a two- to threefold difference was observed between cells transfected with
pTK $\beta 1|-| 2|-|$ vs. pTK $\beta 1|+| 2|+|$ |Fig. 1B, lanes 6-9; summarized in Fig. 1A). Therefore, sequences contained within the transcribed region of the HSV-TK gene can enable efficient processing and cytoplasmic accumulation of intronless chimeric TK-globin RNAs.

\section{Localization of an HSV-TK sequence element mediating intron-independent gene expression}

To look for a positive, cis-acting sequence element in the HSV-TK gene that might enable intron-independent expression of the human $\beta$-globin gene, we made a 
series of TK-deleted variants of pTK $\beta 1|-| 2|-|$ and pTK $\beta 1(+|2|+\mid($ Table 1; Fig. 2A). Each of these plasmids contains a portion of the transcribed region of the HSVTK gene inserted at the $\mathrm{Ncol}$ site in the $5^{\prime}$-untranslated region of either the CDNA or genomic version of the human $\beta$-globin gene. The relative amounts of the TKglobin chimeric RNAs accumulated in cells transfected with each of these plasmids were determined as described above (Figs. 2B,C; summarized in Fig. 2A). Different HSV-TK sequences were found to differ significantly in their ability to enable cytoplasmic accumulation of globin-like RNA in the absence of introns. For example, whereas the presence of HSV-TK nucleotides 338-752 increased cytoplasmic accumulation of globinlike RNA from intronless transcripts at least 30 -fold (Fig. 2B, lane 5), the presence of HSV-TK nucleotides 442-752 had little effect (Fig. 2B, lane 9). Thus, a sequence contained, at least in part, within HSV-TK nucleotides 338 442 can provide in cis an element necessary for efficient pre-mRNA processing.

To delineate further the region of the HSV-TK gene that contains this element, we constructed additional plasmids containing insertions of smaller and smaller portions of the nucleotide 338-752 region of the HSVTK gene (Fig. 2A). Analysis of the globin-like RNAs accumulated in cells transfected with these plasmids indicated that the presence of HSV-TK nucleotides 361-479 is sufficient to enable significant cytoplasmic accumulation of globin-like RNA (Fig. 2C, lanes 7-10). However, the presence of nucleotides $411-479$ is not sufficient (Fig. 2C, lanes 11-14). Therefore, nucleotides $361-479$ of the HSV-TK gene contain a positive, cis-acting sequence element that enables intron-independent processing of $\beta$-globin transcripts, with at least part of this element being contained within nucleotides $361-410$. We name such sequence elements PPEs, for pre-mRNA processing enhancers, because they can substitute for introns in providing a function necessary for the efficient processing and transport of pre-mRNAs.

\section{HSV-TK PPE enables cytoplasmic accumulation of $\beta$-globin RNA in the absence of splicing}

One trivial possibility is that the TK-globin chimeric RNA accumulated in the cytoplasm of cells transfected with pTK119 $\beta 1|-| 2|-|$ because the presence of cryptic splice sites enabled splicing to occur despite the absence of known introns. To test this hypothesis, we performed an additional structural analysis of the chimeric RNA accumulated in the cytoplasm using a reverse transcriptase-polymerase chain reaction (RT-PCR) assay with primers corresponding to sequences near the $5^{\prime}$ and $3^{\prime}$ ends of the RNA (Fig. 3). All of the TK-globin chimeric RNAs accumulated in cells transfected with the intronless plasmid pTK119 $1|-| 2|-|$ were similar in size to the processed TK-globin chimeric RNAs accumulated in cells transfected with the intron-containing plasmid pTK $119 \beta 1|+| 2|+|$ (Fig. 3, lane 4 vs. 5 ). No bands corresponding to cryptically spliced products were detected. Neither were discontinuities in the RNA detected by $\mathrm{S} 1$ nuclease mapping with a probe homologous to $\mathrm{pTK} 119 \beta 1(-|2|-\mid$ (data not shown). S1 mapping with a $3^{\prime}$-end-labeled probe homologous to the $3^{\prime}$ end of the $\beta$-globin gene indicated that PPE-containing transcripts were cleaved and polyadenylated utilizing the normal globin polyadenylation signal (data not shown). Therefore, we conclude that the PPE contained within nucleotides $361-479$ of the HSV-TK gene can mediate proper processing and transport of human $\beta$-globin-like transcripts in the absence of splicing.

Table 1. Summary of structures of the TK-globin chimeric genes studied here

\begin{tabular}{|c|c|}
\hline Plasmid $^{\mathbf{a}}$ & HSV-TK nucleotide residues inserted (altered) into globin NcoI site \\
\hline $\mathrm{p} \beta 1|+| 2 \mid+)^{\mathrm{b}}$ & - \\
\hline $\mathrm{p} \beta 1|-| 2 \mid-)^{\mathrm{c}}$ & - \\
\hline pTK $\beta 1|-| 2 \mid-1$ & $59-1238$ \\
\hline pTK583ß1 $|-| 2 \mid-1$ & $170-752$ \\
\hline pTK415ß1|-|2|-1 & $338-752$ \\
\hline pTK311ß1|-|2|-1 & $442-752$ \\
\hline pTK $142 \beta 1|-| 2 \mid-1$ & $338-479$ \\
\hline pTK $119 \beta 1(-12)-1$ & $361-479$ \\
\hline pTK $69 \beta 1|-| 2 \mid-1$ & $411-479$ \\
\hline pTK $38 \beta 1|-| 2 \mid-1$ & $338-479$ (delete $341-444$ ) \\
\hline pTK119AS $\beta 1|-| 2 \mid-1$ & $361-479$ antisense \\
\hline pTK119X $\beta 1|-| 2 \mid-1$ & $361-479(438 \mathrm{G} \rightarrow \mathbf{A} ; 433 \mathrm{C} \rightarrow \mathbf{G})$ \\
\hline p2XTK $119 \beta 1|-| 2 \mid-1$ & $361-479: 361-479(438 \mathrm{G} \rightarrow \mathbf{A} ; 433 \mathrm{C} \rightarrow \mathbf{G})$ \\
\hline pTK119LSO $\beta 1(-|2|-)$ & $361-479(438 \mathrm{G} \rightarrow \mathbf{A} ; 433 \mathrm{C} \rightarrow \mathbf{G} ; 407-419 \text { ATCTACACCACA } \rightarrow \text { TAGTAGATCTAGA })^{\mathrm{d}}$ \\
\hline pTK119LS1 $\beta 1|-| 2|-|$ & $361-479(438 \mathrm{G} \rightarrow \mathbf{A} ; 433 \mathrm{C} \rightarrow \mathbf{G} ; 416-421 \text { ACACAA } \rightarrow \text { AGATCT })^{d}$ \\
\hline pTK119LS2 $\beta 1|-| 2 \mid-)$ & $361-479(438 \mathrm{G} \rightarrow \mathbf{A} ; 433 \mathrm{C} \rightarrow \mathbf{G} ; 422-427 \text { CACCGC } \rightarrow \text { AGATCT })^{d}$ \\
\hline
\end{tabular}

${ }^{2}$ Only the cDNA version of each plasmid is shown; the genomic version of each variant, containing IVS1 and IVS2, was made likewise. ${ }^{b} \mathrm{p} \beta 1|+| 2|+|$ is the parental starting plasmid; it contains nucleotide residues -812 through +2156 of the human $\beta$-globin gene, including IVS1 and IVS2.

${ }^{c} p \beta 1(-|2|-)$ is identical to $p \beta 1|+| 2|+|$ except for the precise deletion of IVS1 and IVS2.

'A unique BglII site $\left(5^{\prime}\right.$-AGATCT-3') was introduced into each plasmid during the mutagenesis. 
Figure 2. Regions of the HSV-TK gene differ in their ability to enable intron-independent expression of the human $\beta$-globin gene. $(A)$ Summary of the structures of the plasmids containing different portions of the HSV-TK gene inserted into the Ncol site of the human $\beta$-globin gene and the data obtained with them. The schematic diagrams indicate the regions of the HSVTK gene inserted into the CDNA and genomic versions of the human $\beta$-globin gene as described in Table 1. The symbols are the same as those described in the legend to Fig. 1. Only the TK part of the name of each plasmid is stated. The column at right indicates the amount of TK-globin chimeric RNA accumulated in the cytoplasm of cells transfected in parallel with the cDNA vs. corresponding genomic version of each pair of plasmids. These data were determined as described in the legend to Fig. 1 from two to four experiments similar to the ones shown in $B$ and $C .(B, C)$ Autoradiographs of quantitative $S 1$ nuclease mapping analyses of the TK-globin chimeric RNAs accumulated in cells transfected in parallel with the pairs of plasmids containing the TK-globin hybrid genes shown in $A$.$$
\text { A }
$$

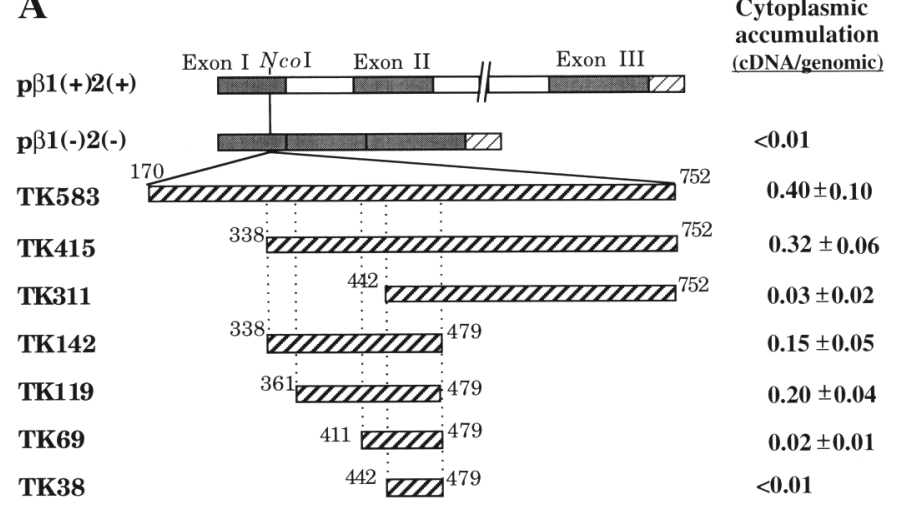

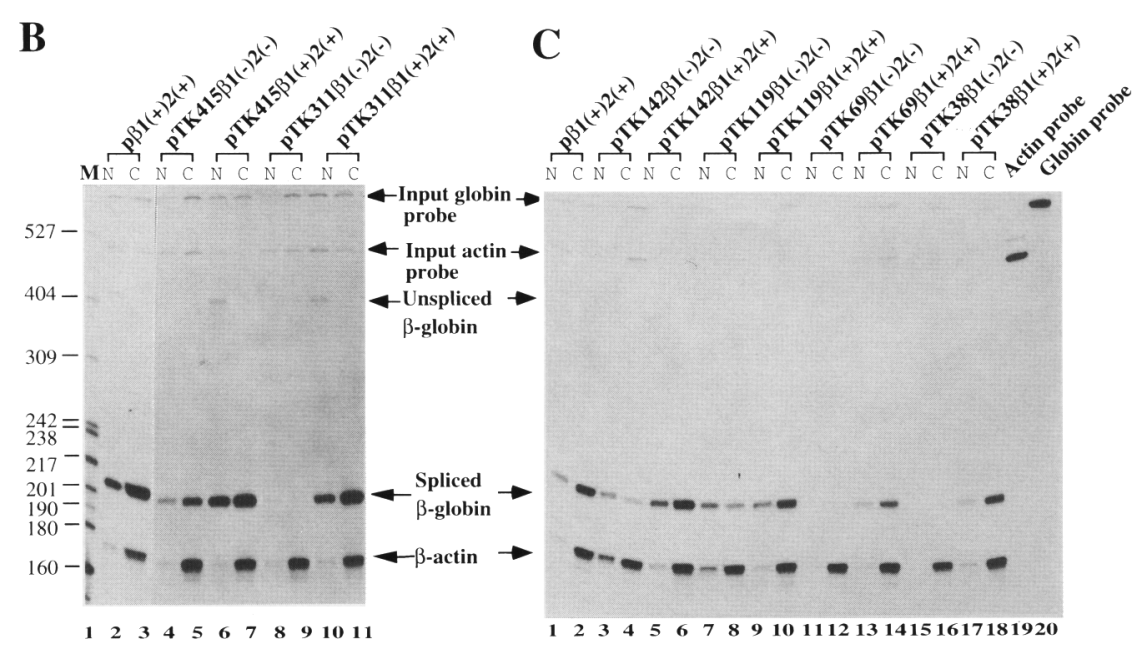

Also noteworthy is the fact that transcripts containing both HSV-TK PPE and the globin introns were also properly processed, in this case with efficient excision of the introns as well (e.g., Fig. 3, lane 5 vs. 4; Fig. 2C, lane 10). Thus, regardless of the presence of introns, primary transcripts containing this HSV-TK PPE are processed properly as well as transported efficiently to the cytoplasm.

\section{Effect of duplication and orientation of the 119-nucleotide HSV-TK sequence element}

Although insertion of HSV-TK nucleotides 361-479 into the NcoI site of the human $\beta$-globin gene leads to fairly efficient rescue of the defects in processing of intronless $\beta$-globin-like transcripts, it enables cytoplasmic accumulation of globin RNA to a level only half of that obtained when nucleotides 59-1238 are inserted into the $\beta$-globin gene (Figs. 1 and 2). One hypothesis to explain this finding is that HSV-TK contains a second PPE that cooperates with the one identified here to enable more efficient RNA processing. To partially test this hypothesis, we constructed the plasmids p2xTK119ß1|-|2|-1 and $22 \times T K 119 \beta 1|+| 2 \mid+1$, which contain two copies in tandem of HSV-TK nucleotides 361-479 inserted at the $N c o I$ site of the human $\beta$-globin gene (Fig. 4A). Duplication of this HSV-TK sequence element resulted in at least a twofold increase in cytoplasmic accumulation of globin-like RNA in the absence of introns (Fig. 4B, lanes 10-13 vs. 6-9; summarized in Fig. 4A). Thus, two copies of this 119-nucleotide HSV-TK sequence element can function at least additively in permitting intron-independent gene expression. The HSV-TK gene probably contains a second PPE yet to be mapped (see Discussion).

To determine whether this novel sequence element functions in an orientation-dependent manner, we constructed the plasmids pTK119AS $\beta 1|-| 2|-|$ and pTK119AS $\beta 1|+| 2|+|$ in which HSV-TK nucleotides $361-479$ were inserted at the Ncol site of the human $\beta$-globin gene, but in the antisense orientation (Fig. 4A). Whereas cells transfected with pTK1 $19 \beta 1|-| 2|-|$ accumulated the chimeric RNA efficiently (Fig. 4B, lanes 6-9), cells transfected with pTK119AS $\beta 1|-| 2|-|$ failed to do so (Fig. 4B, lanes 14-17; summarized in Fig. 4A). Thus, the orientation of this inserted HSV-TK sequence element is important, consistent with its functioning at the RNA level.

\section{Mutations in this PPE that affect its ability to mediate intron-independent gene expression}

To identify bases within this 119-nucleotide HSV-TK sequence element required for intron-independent 


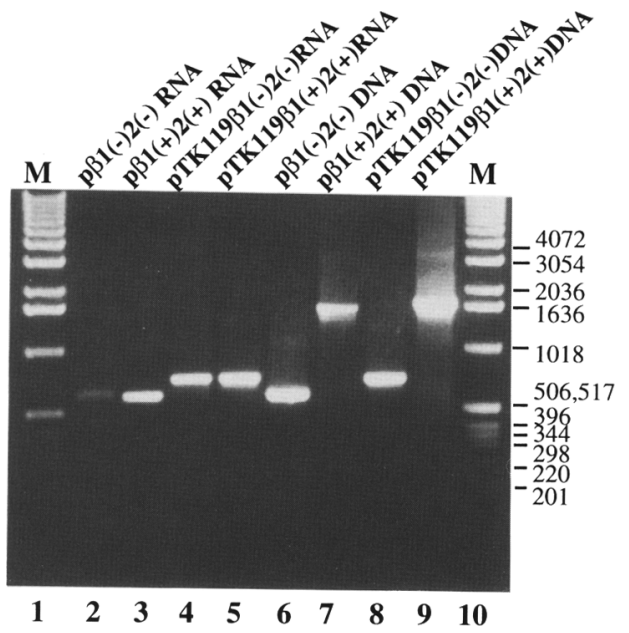

Figure 3. Intronless TK-globin chimeric RNAs accumulate in the cytoplasm unspliced. Portions of the cytoplasmic RNA samples from the experiments shown in Fig. 1B, lanes 3 and 5, and Fig. 2C, lanes 8 and 10, were reverse-transcribed using an oligonucleotide primer complementary to a sequence near the polyadenylation signal of the human $\beta$-globin gene; afterward, the resulting cDNAs were amplified by PCR (lanes 2-5). As controls, the plasmid DNAs used in the transfections were PCR-amplified in parallel (lanes 6-9). Shown here is a photograph of an ethidium bromide-stained, $1.5 \%$ agarose gel in which the PCR products were fractionated by electrophoresis. Lanes 1 and 10 contained 1-kb ladder DNA (BRL).

gene expression, we constructed the plasmids pTK119LSO $\beta 1(-|2|-\mid, \quad$ pTK119LS1 $\beta 1|-| 2|-|$, and pTK119LS2 $\beta 1|-| 2|-|$ and their corresponding intron- containing versions. These plasmids are derivatives of pTK $119 \beta 1|-| 2|-|$ and pTK $119 \beta 1|+| 2|+|$, respectively, into which linker-scanning substitution mutations had been introduced into the nucleotide 399-432 region of the inserted HSV-TK sequence (Fig. 5A; Table 1). The mutations introduced in pTK119LSO $\beta 1|-| 2|-|$ led to an order-of-magnitude reduction in the cytoplasmic accumulation of the chimeric RNA (Fig. 5B, lanes 10-13 vs. 6-9; summarized in Fig. 5A). On the other hand, those mutations introduced in pTK119LS1 $\beta 1|-| 2|-|$ and pTK119LS2 $\beta 1|-| 2|-|$ still enabled the RNA to accumulate at one-third and two-thirds, respectively, of the levels obtained with the unmutated PPE (Fig. 5B, lanes 1421 vs. $6-9$; summarized in Fig. $5 \mathrm{~A}$ ). Thus, we conclude that specific bases within nucleotides $399-432$ of this 119-nucleotide HSV-TK sequence are important for PPE function.

\section{A cellular $68-k D$ protein specifically binds to RNA containing this 119-nucleotide HSV-TK sequence}

Pre-mRNAs are usually associated in the nucleus with distinct sets of hnRNPs. To look for nuclear factors that bind specifically to RNA corresponding to transcripts of the 119-nucleotide HSV-TK sequence element (i.e., rTK119|, we synthesized radiolabeled rTK119 using T7 polymerase and the plasmid pT7/TK119. The labeled transcripts were purified, incubated with extract made from nuclei of HeLa or COS cells, and exposed to UV light to cross-link the bound protein to the radiolabeled RNA. After digestion of the unprotected RNA with RNase A, the RNA-protein adducts were resolved by
A

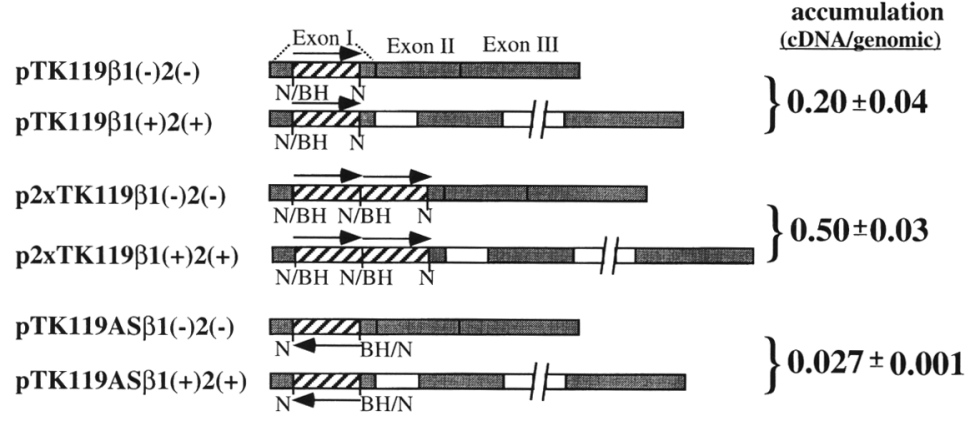

B

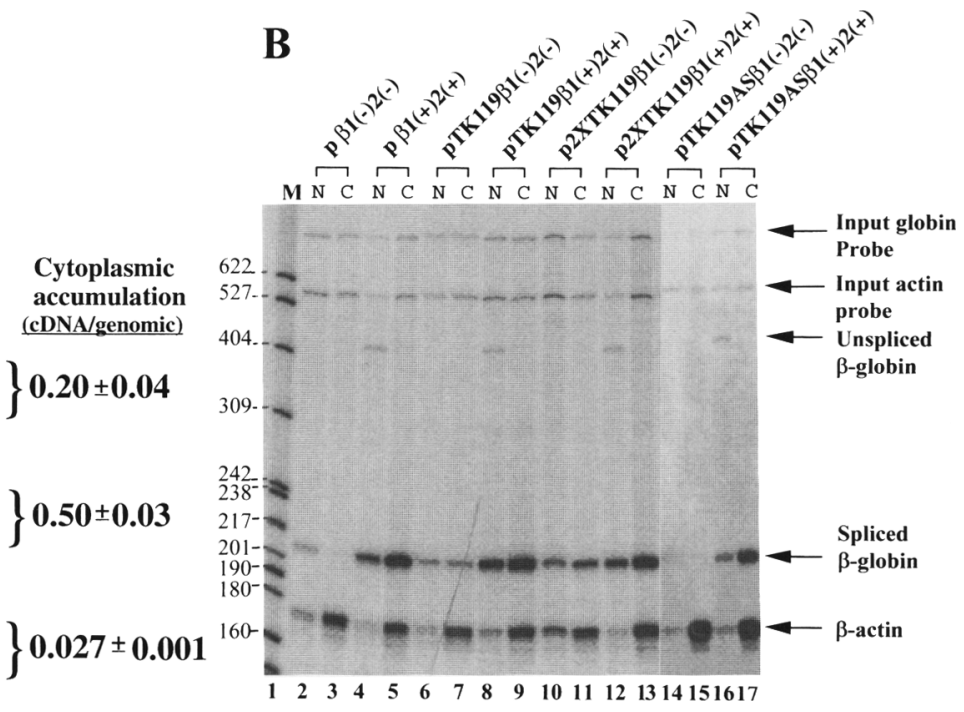

Figure 4. Effects of duplication and orientation of the HSV-TK PPE . (A) Summary of the structures of the plasmids containing an insertion into the $\beta$-globin gene of HSV-TK nucleotides 361-479 in tandem copies or in the antisense orientation, and the data obtained with them. The arrows indicate the orientation of the HSV-TK sequences. (BH) BspHI. All other symbols are the same as those described in the legend to Fig. 1. The data summarized at right were obtained as described in the legend to Fig. 1, from two experiments similar to the one shown in $B .|B|$ Autoradiographs of the S1 nuclease-protected DNA fragments resulting from an experiment performed as described in the legend to Fig. 1, with the plasmids shown in $A$. 
Figure 5. Mutations in the HSV-TK PPE alter its ability to enable intron-independent expression of the human $\beta$-globin gene. $(A)$ Summary of the structures of the plasmids containing linker-scanning substitution mutations in the inserted 119-nucleotide HSV-TK sequence element and the abilities of these variants to enable intron-independent gene expression. The schematic diagrams at left indicate the sequence of the NruI-XhoI region of the 119nucleotide HSV-TK sequence element present in each plasmid; the underlined, boldface letters highlight the altered nucleotides. All other symbols are the same as those described in the legend to Fig. 1 . The data summarized at right were obtained as described in the legend to Fig. 1, from two experiments similar to the one shown in $B$. (B) Autoradiograph of an S1 nuclease mapping analysis of the globin-like RNAs accumulated in cells transfected with each of the mutant plasmids shown in $A$.
A
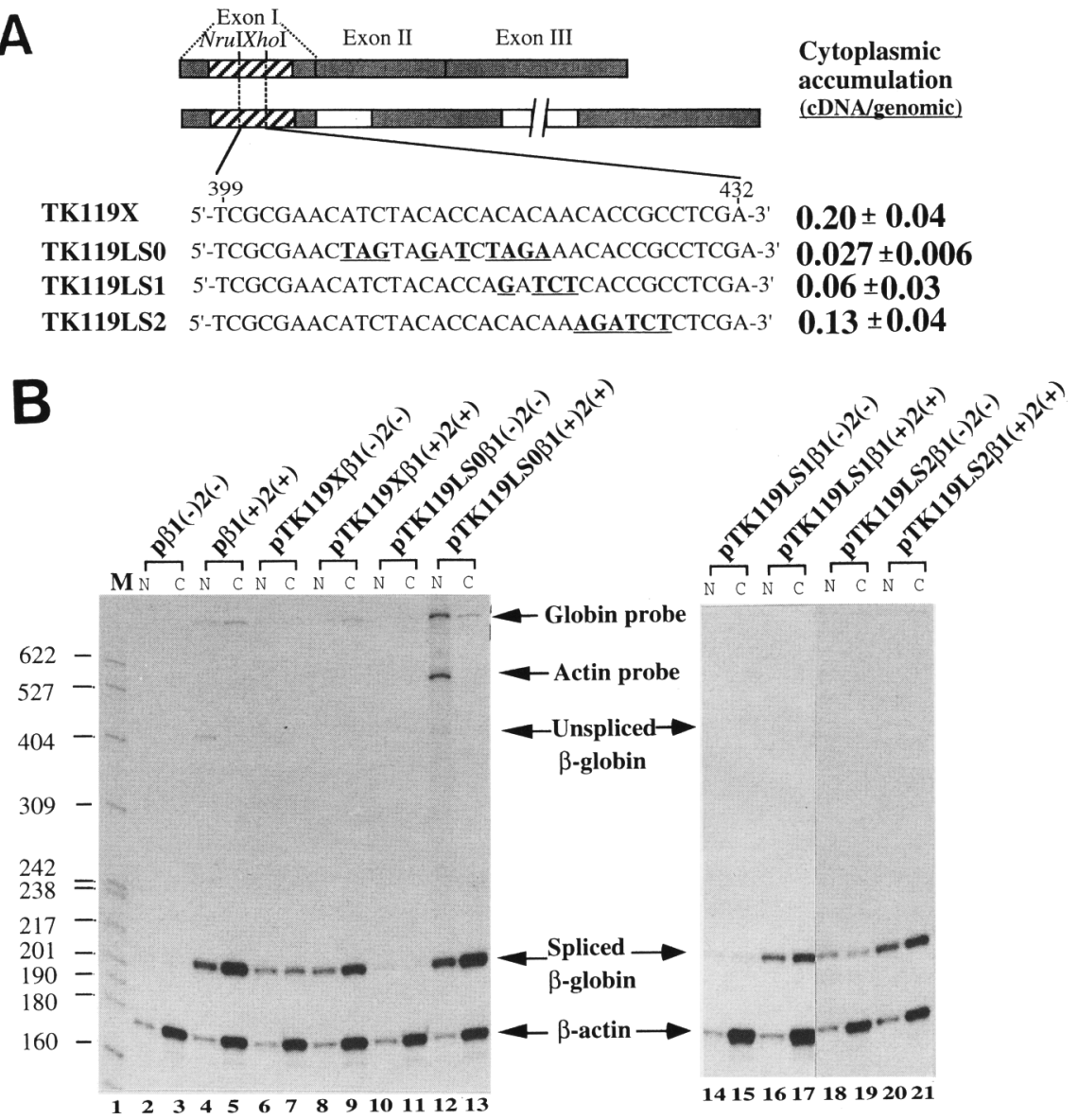

SDS-PAGE (Fig. 6A). Several proteins were found to cross-link with rTK119. However, only the binding of the $\sim 68-\mathrm{kD}$ protein was competed in a sequence-specific manner (Fig. 6B). The intensity of the other abundantly cross-linked factor, corresponding to a protein $\sim 34 \mathrm{kD}$ in size, varied between experiments (e.g., Fig. 6A, lane 2 vs. 6B, lane 1 ) and cell extracts (Fig. 6A, lane 2 vs. 3). Quite likely, this latter band corresponds to a proteolytic prod-
Figure 6. A cellular $68-\mathrm{kD}$ protein specifically binds to rTK119. (A) Autoradiograph of SDS-PAGE analysis of the proteins that UV-cross-link with rTK119. Full-length, ${ }^{32} \mathrm{P}$-labeled $\mathrm{TTK} 119$ was prepared and incubated with 5-10 $\mu \mathrm{g}$ of HeLa (lane 2) or COS (lane 3) cell nuclear extract and exposed to UV irradiation as described in Materials and methods. After digestion with RNase A, the proteins were denatured and fractionated by electrophoresis in an SDS-12\% polyacrylamide gel. Lane 1 contained ${ }^{14} \mathrm{C}$-labeled Rainbow markers (Amersham). (B) Autoradiograph of competition UV-cross-linking experiment performed to determine the sequence specificity of the protein-rTK119 binding reactions. HeLa cell nuclear extract was preincubated with the indicated relative molar quantities of unlabeled, specific (rTK119; lanes 1-5) or nonspecific (p $\alpha 19$; lanes 6-10) competitor RNA prior to incubation with radiolabeled rTK1 19 and processing as described in $A$. The nonspecific competitor RNA, pa19, is a 58-nucleotide RNA synthesized with T7 RNA polymerase from the polylinker region of the cloning vector pT3/T7 19 (Gillis and Malter 1991; BRL).
A
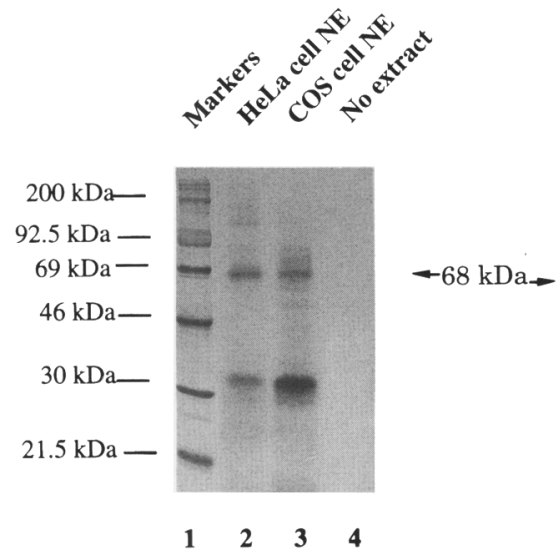

B Specific competitor Non-specific competitor
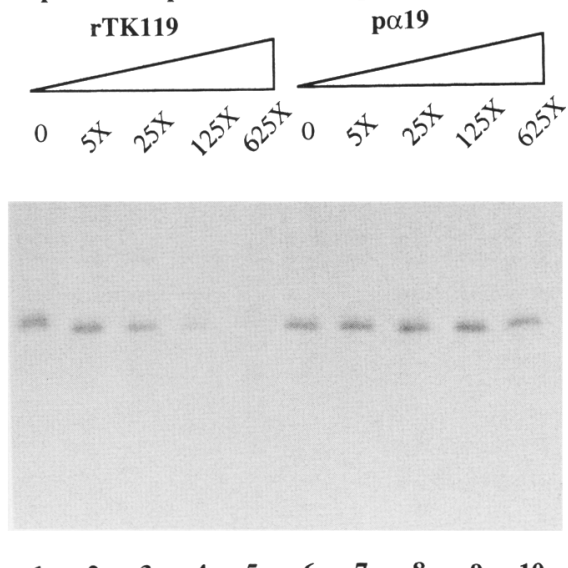

$\begin{array}{llllllllll}1 & 2 & 3 & 4 & 5 & 6 & 7 & 8 & 9 & 10\end{array}$ 
A

\begin{tabular}{|c|c|c|}
\hline$\underset{\text { Nrul Xhol }}{7_{\text {promoler }}^{N}}$ & UV-crosslinking & $\begin{array}{l}\text { Cytoplasmic } \\
\text { accumulation } \\
\text { (DDNA/genomic) }\end{array}$ \\
\hline & & $0.20 \pm 0.04$ \\
\hline F119LSO & 11 & 2 \\
\hline 9LS1 & $\begin{array}{l}0.45 \pm 0.11 \\
0.60+0.13\end{array}$ & \\
\hline LS2 & $\mathbf{0 . 6 0} \pm \mathbf{0 . 1 3}$ & $0.13 \pm 0.04$ \\
\hline
\end{tabular}

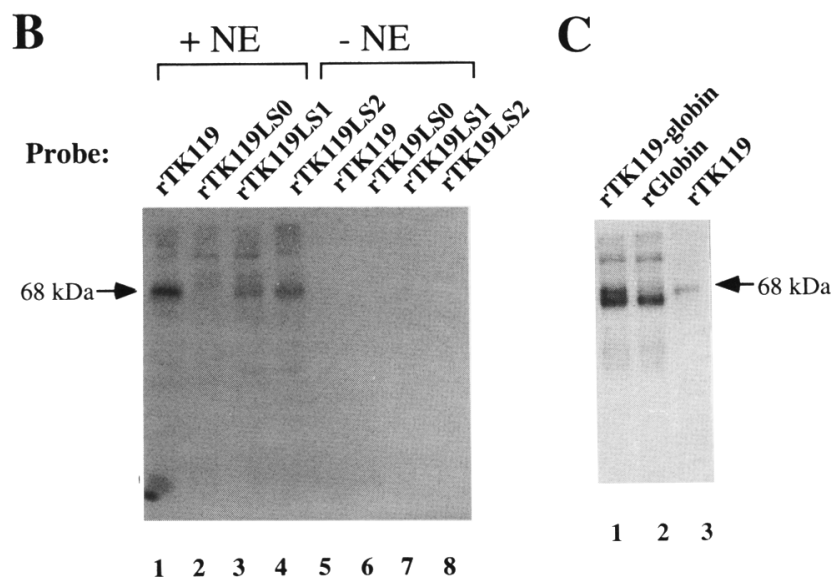

Figure 7. Binding of the $68-\mathrm{kD}$ protein correlates with PPE function. $(A)$ Schematic diagram of the plasmids, with linkerscanning substitution mutations in the PPE, used to synthesize the radiolabeled rTK119, rTK119LS0, rTK119LS1, and rTK119LS2 RNAs and a summary of the UV-cross-linking data obtained with these RNAs. The sequence alterations present in these plasmids correspond to the ones shown in Fig. 5A. The second column indicates the binding of the $68-\mathrm{kD}$ protein to each of these RNAs relative to its binding to rTK119 as determined by quantitative analysis with a PhosphorImager of two independent experiments similar to the one shown in $B$. The last column is taken from the data in Fig. 5. $(B)$ Autoradiograph of UV-cross-linking assays performed with the RNAs synthesized from the plasmids shown in $A$. (Lanes 1-4) Presence of nuclear extract from HeLa cells; (lanes 5-8) absence of nuclear extract. $(C)$ Differential binding of the $68 \mathrm{-kD}$ protein to intronless $\beta$-globin transcripts containing (lane 1) or lacking (lane 2) HSV-TK nucleotides 361-479. Full-length, ${ }^{32}$ P-labeled rTK119globin, globin, and rTK119 RNAs were synthesized by in vitro transcription of plasmids pT7/TK119 $\beta 1 /-12(-1$, pT7/ $\beta 1$ $(-|2|-\mid$, and pT7/TK119, respectively. Each RNA was incubated with $5 \mu \mathrm{g}$ of HeLa cell nuclear extract in the presence of $400 \mathrm{ng}$ of nonspecific competitor RNA pa19. UV-cross-linking was performed as described in the legend to Fig. 6.

uct of the $68-\mathrm{kD}$ protein or a nonspecific cross-linking product.

Binding of this $68-\mathrm{kD}$ protein to $\mathrm{rTK} 119$ correlates with the ability of this PPE to enable cytoplasmic accumulation of mRNA in vivo

UV-cross-linking analysis performed with deleted variants of rTK119 indicated that the region of this RNA critical for efficient in vitro binding of the $68-\mathrm{kD}$ protein is located around nucleotides 387-419 (Liu 1994). This same region is also essential for the functioning of this element in vivo (Fig. 2C, lanes 11,12,15,16; summarized in Fig. 2A). To further assess the biological importance of the binding of the $68-\mathrm{kD}$ protein to $\mathrm{rTK} 119$, we examined whether binding of this protein to RNAs containing alterations in this sequence (Fig. 7) correlated with the previously determined abilities of these sequences to enable intron-independent gene expression (Fig. 5). To assay for binding, we first constructed the plasmids pT7/TK119LS0, pT7/TK119LS1, and pT7/TK119LS2 (Fig. 7A). These plasmids are identical in sequence to pT7/TK119 except for the replacement of the NruI$X$ hol region with the corresponding region from plasmids pTK119LSO $\beta 1|-| 2 \mid-1$, pTK119LS1 $\beta 1|-| 2 \mid-1$, and pTK119LS2 $\beta 1|-| 2|-|$, respectively (Fig. 5A). These plasmid DNAs were cleaved with $\mathrm{NcoI}$ and transcribed with T7 RNA polymerase in parallel reactions to make rTK119, rTK119LS0, rTK119LS1, and rTK119LS2 radiolabeled to similar specific activities. Identical amounts of each RNA were incubated with equal amounts of HeLa cell nuclear extract and processed as in the UVcross-linking experiments described above. The relative abilities of these RNAs to bind the $68-\mathrm{kD}$ protein were determined by quantitative analysis of the relative intensities of the RNA-protein adducts (Fig. 7B). These data (summarized in Fig. 7A) indicate that the efficiencies with which these mutant RNAs bind the $68-\mathrm{kD}$ protein correlate well with their abilities to enable cytoplasmic accumulation of intronless globin-like RNA.

If sequence-specific binding of the $68-\mathrm{kD}$ protein to rTK 119 is responsible for enabling proper processing and cytoplasmic accumulation of intronless TK119-globin chimeric transcripts, this protein would be expected to bind transcripts synthesized from pTK $119 \beta 1|-| 2|-|$ but not ones synthesized from $\mathrm{p} \beta 1(-|2|-1$. To test this hypothesis, radiolabeled RNAs corresponding to these transcripts were synthesized with T7 RNA polymerase, incubated with HeLa cell nuclear extract in the presence of the nonspecific competitor RNA p $\alpha 19$, and exposed to UV light as described above (Fig. $7 \mathrm{C}$ ). Whereas transcripts containing this 119-nucleotide HSV-TK sequence specifically cross-linked with the $68-\mathrm{kD}$ protein in vitro (Fig. 7C, lane 1), the intronless $\beta$-globin transcripts did not (Fig. 7C, lane 2). These data indicate that the pre-mRNAs synthesized from $\mathrm{p} \beta 1|-| 2|-|$ and pTK1 $19 \beta 1(-12(-)$ are differentially bound by the $68-\mathrm{kD}$ protein, with the presence of the 119-nucleotide HSVTK sequence being responsible for this difference. Thus, we conclude that binding of this cellular $68-\mathrm{kD}$ protein to this RNA sequence element probably plays an important role in the proper processing and transport of these intronless transcripts.

hnRNP $L$ is the $68-k D$ cellular protein that binds sequence specifically to this HSV-TK PPE

hnRNP $\mathrm{K}$ and hnRNP $\mathrm{L}$ are two RNA-binding proteins $\sim 68 \mathrm{kD}$ in size (Piñol-Roma et al. 1988; Matunis et al. 
Figure 8. The cellular $68-\mathrm{kD}$ protein that specifically binds the HSV-TK PPE is immunologically related to hnRNP L. (A) Autoradiograph of an $8 \mathrm{M}$ urea/ $6 \%$ polyacrylamide gel indicating the quality and relative specific activities of the radiolabeled RNAs used in the UV-cross-linking experiment shown in $B$. (M) Markers of MspI-cut pBR322 DNA. rPsp72 is a 97-nucleotide RNA synthesized with T7 RNA polymerase from the polylinker region of the cloning vector Psp72 (Promega). (B) Autoradiograph of an SDS- $12 \%$ polyacrylamide gel of the UV-cross-linked proteins immunoprecipitated with mouse preimmune serum (lane 2) or antisera specific to hnRNP $\mathrm{K}(3 \mathrm{C} 2$ and $12 \mathrm{G} 4$; lanes 3 and 4, respectively) or hnRNP L (4D11; lanes 5-9). UVcross-linking and immunoprecipitation assays were carried out as described in Materials and methods. (Lane 1) Rainbow protein markers (Amersham).

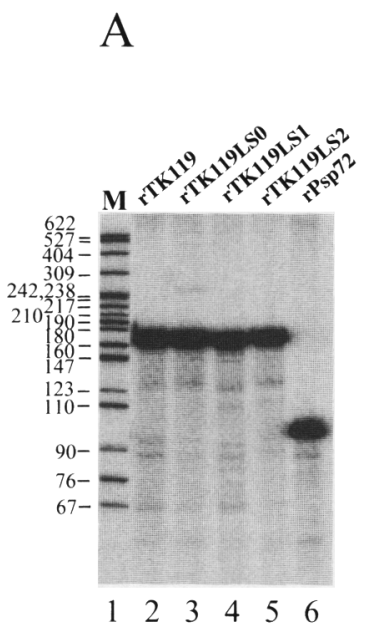

B

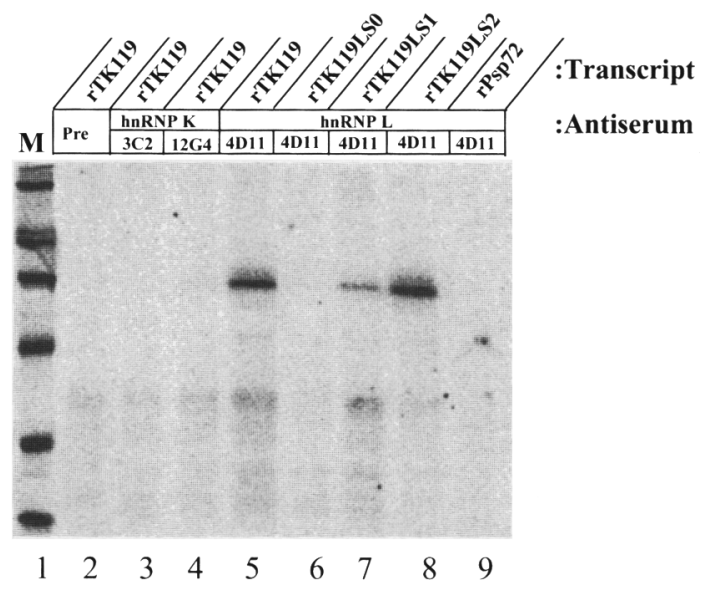

1992). To determine whether the $68-\mathrm{kD}$ cellular protein identified above might be one of these proteins, we performed UV-cross-linking assays followed by immunoprecipitation with appropriate specific antisera (generous gifts from the laboratory of G. Dreyfuss, University of Pennsylvania School of Medicine, Philadelphia). The 68$\mathrm{kD}$ protein that cross-linked with $\mathrm{rTK} 119$ was immunoprecipitated with an anti-hnRNP L-specific serum but not with a preimmune serum or two anti-hnRNP K-specific sera (Fig. $8 B$, lane 5 vs. $2-4$ ). To confirm the specificity of this binding reaction, we also performed UVcross-linking immunoprecipitation assays with the mutant RNAs described above. As expected, the relative amounts of radiolabeled $68-\mathrm{kD}$ material immunoprecipitated with the hnRNP L-specific antiserum were similar to the relative amounts detected above by cross-linking alone (Fig. 8B, lanes $5-8$ vs. Fig. 7B, lanes $1-4$ ). Thus, the $68-\mathrm{kD}$ cellular protein cross-linked to the rTK119 is immunologically related to hnRNP L.

To prove that this $68-\mathrm{kD}$ protein is hnRNP $\mathrm{L}$, we re- peated the RNA UV-cross-linking assays with recombinant hnRNP L synthesized in a reticulocyte lysate. As expected, in vitro-synthesized hnRNP L cross-linked with rTK119 (Fig. 9, lane 1). Furthermore, the relative efficiencies of cross-linking of this recombinant protein with the various mutant and control RNAs /data not shown) were found to be very similar to those observed with the $68-\mathrm{kD}$ protein present in the nuclear extract (Fig. 7).

To confirm the specificity of this interaction, we also performed competition UV-cross-linking assays with radiolabeled rTK119 and various amounts of unlabeled rTK119, rTK119LS0, rTK119LS1, rTK119LS2, rPsp72, and pa19. Once again, the data obtained from this experiment (Fig. 9) were consistent with the direct UV-crosslinking experiments described above (Figs. 7 and 8), and a good correlation was found between the ability of an RNA to compete for binding recombinant hnRNP L and its ability to function as a PPE. Thus, we conclude that the sequence-specific binding of the cellular $68-\mathrm{kD}$ pro-
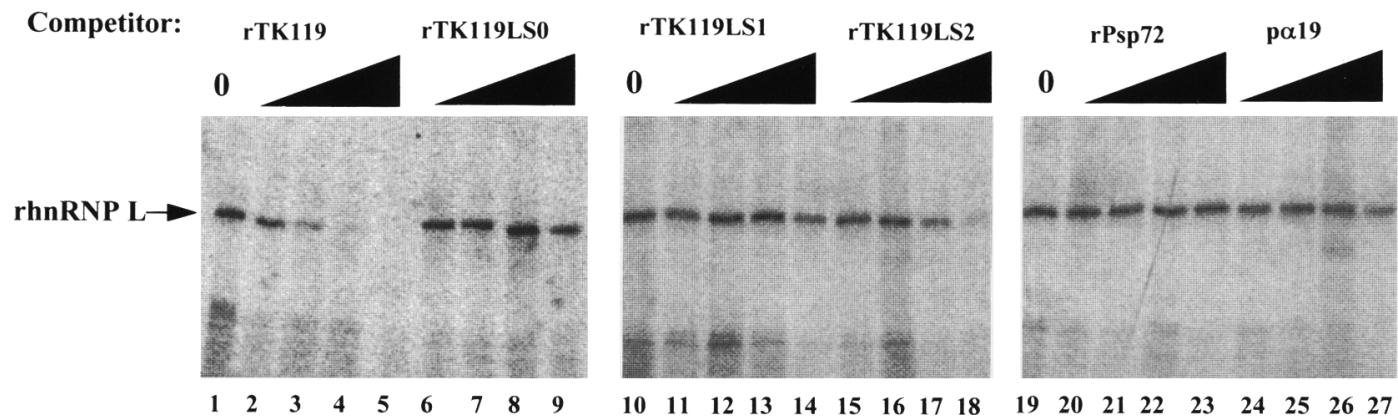

Figure 9. Relative abilities of mutants in the HSV-TK PPE to compete for binding recombinant hnRNP L. Shown here are autoradiographs of UV-cross-linking competition assays. Various amounts $(4,20,100,500 \mathrm{ng})$ of the indicated unlabeled RNAs as competitors were incubated with radiolabeled rTK119 in the presence of recombinant hnRNP L synthesized in a reticulocyte lysate and exposed to UV light prior to electrophoresis in SDS-10\% polyacrylamide gels. 
tein hnRNP L to the PPE contained within HSV-TK nucleotides $361-479$ probably plays a role in the intronindependent processing and transport of the globin-like transcripts studied here.

\section{Discussion}

We have shown here that the transcribed region of the naturally intronless HSV-TK gene contains at least one positive, cis-acting sequence element that can enable the proper processing and transport of transcripts synthesized from an intronless variant of the highly introndependent human $\beta$-globin gene. We have (1) localized to a 119-bp region a sequence that can mediate this effect (Fig. 2), (2) shown that this novel sequence element truly enables cytoplasmic accumulation of mRNAs in the absence of splicing (Fig. 3), (3) provided evidence that this sequence probably functions at the RNA level (Fig. 4), (4) demonstrated that it functions in an orientation-dependent manner (Fig. 4), and (5) shown that this element functions more efficiently when present in more than one copy (Fig. 4). We named sequence elements with this novel set of properties PPEs. We went on to show that hnRNP L, an abundant $68-\mathrm{kD}$ cellular protein of previously unknown function, binds in a sequence-specific manner to transcripts containing this HSV-TK PPE (Figs. 6-9), with binding of hnRNP L to this PPE correlating with the ability of this PPE to enable intron-independent cytoplasmic accumulation of mRNA (Figs. 5, 7, 8 , and 9). Therefore, we conclude that this specific protein-RNA interaction can play an important role in mediating proper processing and nuclear export of intronless pre-mRNAs.

\section{A sequence element contained within the HSV-TK gene can mediate intron-independent gene expression}

Insertion of most of the transcribed region of the HSVTK gene can, in large part, relieve the requirement for an intron for efficient cytoplasmic accumulation of intronless human $\beta$-globin transcripts (Fig. 1). Our deletion mapping data (Fig. 2) indicated that an element contained within nucleotides $361-479$ (relative to the transcription initiation site) of the HSV-TK gene can partially provide this function. Greenspan and Weissman (1985) and Buchman and Berg (1988) had noted previously that nonoverlapping sequences transcribed from the HSV-TK gene can accumulate in mammalian cells in the absence of intron excision. The simplest interpretation of their data was that intronless HSV-TK transcripts lack negative, cis-acting sequence elements that prevent nuclear export in the absence of splicing. In view of the findings presented here, we now reinterpret their data to indicate instead that the HSV-TK gene probably contains at least two functionally similar sequence elements. Consistent with this conclusion are our observations that (1) the HSV-TK sequence element mapped here functions with approximately one-half the efficiency that the full-length HSV-TK gene does (Fig. 1 vs.
Fig. 2), and (2) insertion of two copies of this sequence element results in a twofold increase in the cytoplasmic accumulation of intronless transcripts (Fig. 4). Thus, we hypothesize that two or more copies of this element may act in a cooperative or additive manner to enhance the efficiency of processing and nuclear export of premRNAs.

Pre-mRNAs differ considerably in their requirement for an intron for efficient processing. Introns are absolutely required for expression of the human $\beta$-globin (Ryu 1989; Collis et al. 1990), rabbit $\beta$-globin (Buchman and Berg 1988), human PNP (Jonsson et al. 1992), and human TPI (Nesic et al. 1993) genes. On the other hand, some naturally intron-containing genes [i.e., those encoding polyoma middle $T$ antigen (Treisman et al. 1981) and cellular thymidine kinase (Gross et al. 1987)] appear to be considerably less dependent on the presence of introns for processing of their transcripts. Possibly, premRNAs differ in their efficiencies of processing in the absence of splicing because of differences in (1) the numbers and relative effectiveness of their PPEs, and $(2)$ the abundances and specific activities in the cell of the trans-acting factors that recognize these PPEs.

Several families of viruses have been shown to contain cis-acting sequence elements that enable efficient cytoplasmic accumulation of their own transcripts in the absence of splicing. These viruses include human immunodeficiency virus (HIV) (Rosen et al. 1988; Hadzopoulou-Cladaras et al. 1989; Malim et al. 1989), MasonPfizer monkey virus (Bray et al. 1994), and hepatitis B virus (Huang and Liang 1993; Huang and Yen 1994). In the case of HIV, the trans-acting factor, Rev, which recognizes the cis-acting Rev response element (RRE), is virally encoded (Cullen et al. 1988; Emerman et al. 1989; Felber et al. 1989; Hammarskjold et al. 1989; Malim et al. 1989). Interestingly, sequences contained within the transcribed region of the naturally intronless cellular gene c-jun can also enable intron-independent gene expression (X. Liu and J.E. Mertz, unpubl.). Thus, cellular as well as viral genes contain sequence elements that enable processing and transport of mRNA in the absence of splicing. It will be of interest to determine whether these elements are functionally and/or biochemically analogous to the HSV-TK PPE identified here. Quite likely, efficient processing and nuclear export of premRNAs in the absence of splicing in higher eukaryotes require the presence of sequence elements functionally analogous to the one identified here. However, these different sequence elements may well fall into classes recognized by different trans-acting factors that direct transcripts containing them to different RNA processing pathways.

\section{Role of HSV-TK PPE in intron-independent gene expression}

Much evidence indicates that the requirement of introns for the efficient expression of intron-dependent genes is post-transcriptional in nature (Gruss et al. 1979; Hamer 
and Leder 1979; Buchman and Berg 1988; Ryu and Mertz 1989; Collis et al. 1990; Huang and Gorman 1990; Nesic et al. 1993). The HSV-TK PPE identified here probably also acts post-transcriptionally. First, the presence of this element in an intron-containing gene has little effect on cytoplasmic accumulation of the resulting mRNA (e.g., Fig. 2C, lane 10 vs. 2). Second, the functioning of this element is orientation dependent (Fig. 4). Third, transcripts containing this sequence specifically interact with a $68-\mathrm{kD}$ protein present in nuclear extracts (Fig. 6). Fourth, a good correlation exists between the binding of this $68-\mathrm{kD}$ protein, hnRNP $\mathrm{L}$, to this RNA element and the latter's ability to function in vivo (Figs. 5-9).

Transcripts synthesized from intronless variants of intron-requiring genes are retained in the nucleus, where they are degraded (Fig. 1; Ryu and Mertz 1989; Collis et al. 1990; Huang and Gorman 1990, and references cited therein). One hypothesis to explain nuclear retention is that specific sequence elements present in transcripts prevent nucleocytoplasmic transport by binding proteins restricted to the nucleus. Splicing signals are obvious candidates for such elements. Another cis-acting sequence element responsible for nuclear retention of premRNAs has been identified in HIV (Brighty and Rosenberg 1994). Nuclear retention can then be overcome by the interactions of trans-acting factors that enable nuclear export (e.g., the HIV-encoded protein Rev) with specific cis-acting sequences present in these transcripts (e.g., RRE). Therefore, specific RNA sequence elements exist that can either positively or negatively regulate nuclear export of mRNAs.

One plausible hypothesis is that hnRNP $\mathrm{L}$ and the HSV-TK PPE identified here function analogously to Rev and RRE, respectively, possibly increasing the kinetics of nuclear export. If so, these factors might enable mRNAs to reach the cytoplasm still containing introns if these introns are excised slowly, but not if they are excised quickly. Thus, it is noteworthy that transcripts containing both the HSV-TK PPE identified here and globin IVS2, an intron that is excised quickly (Lang et al. 1985), accumulate in the cytoplasm lacking both introns IVS1 and IVS2 (Fig. 3, lane 5). On the other hand, a sig. nificant percentage of transcripts containing this same PPE and only globin IVS1, an intron that is excised slowly in the absence of IVS2 (Lang et al. 1985), arrives and accumulates in the cytoplasm still retaining this intron (Greenspan and Weissman 1985). Likewise, the retention of introns in retroviral transcripts may be a consequence of the kinetics of nuclear export being faster than the kinetics of excision of these weak introns when PPE-like elements are present.

In the presence of the HSV-TK PPE identified here, intronless globin-like transcripts are both stabilized in the nucleus and exported to the cytoplasm (Fig. 1B). However, stabilization of RNA in the nucleus need not imply nucleocytoplasmic transport. For example, unspliced HIV transcripts are stabilized, yet restricted to the nuclei of COS cells in the absence of Rev /Cullen et al. 1988; Emerman et al. 1989; Felber et al. 1989; Ham- marskjold et al. 1989; Malim et al. 1989). In human T cells, these same transcripts are degraded (Malim and Cullen 1993). The presence of Rev not only enables the nucleocytoplasmic transport of unspliced viral mRNAs but also acts to stabilize these mRNAs in T cell nuclei. The mechanism of nuclear stabilization remains unclear. Lu et al. (1990) have shown that the presence of the Tat/Rev 5' splice site is essential for the nuclear stability of unspliced transcripts of HIV. We have noted that nucleotides 435-443 (AGG|GUGAGA) of the HSV-TK PPE share significant homology with the $5^{\prime}$ splice site consensus sequence. However, (1) a nucleotide- 438 (GT $\rightarrow \mathrm{AT}$ ) point mutation, predicted to inactivate this putative splice site-like sequence, does not affect its function (Fig. 2C, lanes 7 and 8 vs. Fig. 5B, lanes 6 and 7), and (2) transcripts synthesized from pTK69 $\beta 1|-| 2 \mid-1$ contain this sequence yet fail to accumulate in the cytoplasm (Fig. 2C, lanes 11,12). Therefore, this HSV-TK PPE functions independently of this putative $5^{\prime}$ splice sequence. Thus, we conclude that interaction of this HSV-TK PPE sequence with hnRNP $L$ is probably directly or indirectly responsible for nuclear stabilization of the intronless TK-globin transcripts.

One plausible hypothesis is that stabilization and nuclear export are consequences of proper 3 '-end formation. The presence of introns has been shown to stimulate cleavage and polyadenylation of many pre-mRNAs in vitro (Niwa et al. 1990; Niwa and Berget 1991) and in vivo (Collis et al. 1990; Pandey et al. 1990; Chiou et al. 1991; Liu 1994; Nesic and Maquat 1994). Transport of intronless histone transcripts is stimulated by proper 3'end formation (Eckner et al. 1991). We find that the presence of this HSV-TK PPE in intronless $\beta$-globin transcripts leads to a significant increase in the accumulation of polyadenylated $\beta$-globin-like RNA (X. Liu and J.E. Mertz, unpubl.). Thus, this HSV-TK PPE might function directly or indirectly to facilitate 3 '-end formation.

\section{RNA-protein interactions in pre-mRNA processing}

Nascent transcripts rapidly associate with hnRNP proteins and small nuclear ribonucleoproteins (snRNPs) in a sequence-specific manner (Bennett et al. 1992; Dreyfuss et al. 1993; Matunis et al. 1993). The specific arrangement of hnRNPs on a transcript is likely an important determinant of the subsequent steps in mRNA biogenesis and transport. For example, Swanson and Dreyfuss (1988) have shown that the major hnRNP proteins Al, C, and $D$ bind specifically to the 3 ' ends of the introns of human $\beta$-globin pre-mRNA; however, no specific, highaffinity binding sites for these proteins exist on intronless globin RNAs. Using a UV-cross-linking assay, we observed only one significant difference in the pattern of proteins bound to the intronless $\beta$-globin transcripts containing the 119-nucleotide HSV-TK sequence versus transcripts lacking it, that is, the presence of a band corresponding to a protein $68 \mathrm{kD}$ in size (Fig. $7 \mathrm{C}$ ). Immu- 
noprecipitation with an anti-hnRNP L-specific serum (Fig. 8) and direct UV-cross-linking experiments with recombinant hnRNP L (Fig. 9) indicated that the $68-\mathrm{kD}$ protein is hnRNP L. Binding of hnRNP $\mathrm{L}$ to the transcript was found to correlate with efficient processing and transport of the RNA (Figs. 5, 8, and 9). Thus, we conclude that the binding of hnRNP L probably plays an important role in the proper processing and transport of intronless human $\beta$-globin mRNA containing this HSVTK PPE.

Several hnRNP proteins have been shown to bind RNA in a sequence-specific manner. For example, hnRNP Al binds to 5' splice site-like sequences (Burd and Dreyfuss 1994), hnRNP I binds to polypyrimidine tract sequences (Garcia-Blanco et al. 1989; Patton et al. 1991; Bennett et al. 1992; Ghetti et al. 1992), and hnRNP $\mathrm{K}$ has a high affinity for poly(C)-rich sequences (Swanson and Dreyfuss 1988; Matunis et al. 1992). Specific RNAprotein interactions often regulate important steps in pre-mRNA processing. By mutational analysis, we showed here that hnRNP L binds to RNA with high sequence specificity. HnRNP L is an abundant nuclear protein found in association with some of the nascent transcripts observed in the giant loops of lampbrush chromosomes of amphibian oocytes (Piñol-Roma et al. 1989). At least some of the hnRNP L present in cells exists free from association with previously defined hnRNP complexes (Piñol-Roma et al. 1989). The precise function of hnRNP L is not yet known. One possibility is that hnRNP L functions to shuttle RNAs between the nucleus and cytoplasm, much as hnRNP Al has been shown to do (Piñol-Roma and Dreyfuss 1992). A second possibility is that the binding of this protein helps to ensure the formation of ribonucleoprotein complexes on the nascent transcripts, thereby protecting the RNAs from degradation in the nucleus and, consequently, allowing the RNAs to be efficiently processed and exported to the cytoplasm. A third and not mutually exclusive possibility is that binding of hnRNP L may facilitate recruitment to the RNA of other hnRNP proteins that, subsequently, function in other steps in pre-mRNA processing (e.g., polyadenylation) and transport to the cytoplasm.

\section{Intron-dependent vs. intron-independent gene expression}

We have shown here that a specific sequence element present in the transcribed region of an intronless gene, the HSV-TK gene, can obviate the intron requirement for expression of a highly intron-dependent gene, the human $\beta$-globin gene. Preliminary data indicate that this HSV-TK PPE can also enable expression of an intronless variant of another highly intron-dependent gene, the PNP gene (Liu 1994). Thus, this PPE enables intron-independent processing of several, if not all, pre-mRNAs. In addition, preliminary data indicate that the intronless cellular gene c-jun probably also contains at least one sequence element with a comparable function (X. Liu and J.E. Mertz, unpubl.). Thus, we speculate that many, if not all, intronless cellular and viral genes contain functionally comparable sequence elements.

One problem encountered frequently in trying to efficiently express genes in mammalian cells in vitro or in vivo is very poor expression of the cDNA version of the gene of interest. Possibly, the inclusion in expression vectors of PPEs, such as the one identified here, may enable one to readily achieve efficient expression of intron-dependent genes in the absence of splicing for use in (1) gene therapy, (2) the manufacture of proteins, and (3) basic and applied research.

In summary, we have identified a novel sequence element, called a PPE, that enables cytoplasmic accumulation of mRNAs in the absence of splicing. The HSV-TK PPE mapped here interacts with hnRNP $L$ in a highly sequence-specific manner. This specific RNA-protein interaction probably plays an important role in the ability of this PPE to enable intron-independent gene expression.

\section{Materials and methods \\ Cells, transfections, and nuclear extracts}

The African green monkey kidney cell line CV-1PD was grown in Dulbecco's modified Eagle medium (DMEM) supplemented with $5 \%$ fetal bovine serum as described previously (Good et al. 1988). Cotransfections were performed by a modification of the DEAE-dextran/chloroquine procedure essentially as described previously (Liu and Mertz 1993). The relative transfection efficiencies were determined as described previously (Ryu and Mertz 1989|, by Southern blot analysis of the replicated plasmid DNA present in each sample. HeLa and COS cell nuclear extracts were prepared essentially as described previously (Dignam et al. 1983).

\section{Recombinant plasmids}

All plasmids were constructed by standard recombinant DNA techniques (Sambrook et al. 1989). Plasmid $\mathrm{p} \beta 1|+| 2|+|$ contains a genomic version of the human $\beta$-globin gene (Fig. 1 ). Plasmid $\mathrm{p} \beta 1|-| 2|-|$ is identical in sequence to $\mathrm{p} \beta 1|+| 2|+|$ except for the precise lack of the two $\beta$-globin introns. These plasmids have been described in detail elsewhere (Ryu 1989; Yu et al. 1991|. Plasmids pTK $\beta 1|-| 2|-|$ and $\mathrm{pTK} \beta 1|+| 2|+|$ contain an insertion of nucleotides $59-1238$ (relative to the transcription initiation site) of the HSV-TK gene into the NcoI site in the 5'-untranslated region of the plasmids $\mathrm{p} \beta 1|-| 2|-|$ and $\mathrm{p} \beta 1|+| 2 \mid+1$, respectively (Fig. 1). These plasmids were constructed by ligation after the HSV-TK sequence to be inserted was generated by PCR-based amplification as described previously (Liu 1994). A series of TK-deleted, duplicated, and antisense variants of these TK-globin chimeric plasmids (Figs. 2 and 4; Table 1) was generated in similar fashion (Liu 1994). The construction of pTK $119 \times \beta 1|-| 2|-|$ and pTK119X $\beta 1|+| 2 \mid+1$ and the linker-scanning mutant derivatives of these plasmids (Fig. 5; Table 1) has also been described in detail elsewhere (Liu 1994).

Plasmid pT7/TK119 (Fig. 7) was constructed by insertion of the BspHI- and NcoI-digested PCR fragment of pTK1 $19 \beta 1(-|2|-\mid$ into $N$ col-digested pGEM5Z $|+|$ in the sense orientation. Plasmids pT7/TK119LS0, pT7/TK119LS1, and pT7/TK119LS2 are identical to pT7/TK119 except that they contain the thymidine kinase sequence substitution mutations 
from plasmids pTK119LSO $\beta 1(-|2|-\mid$, pTK119LS1 $\beta 1|-| 2|-|$, and pTK119LS2 $\beta 1|-| 2 \mid-1$, respectively (Table 1$)$. The RNAs synthesized from these plasmids are designated by rTK, followed by the length of the RNA and, where appropriate, the mutation name. Plasmids pT7/TK1 19ß1/-12(-) and pT7/ $\beta 1(-|2|-1$, used to generate the RNAs employed in the experiment shown in Figure 7C, were constructed by insertion of the HindIII- and XbaI-digested PCR fragments of pTK1 $19 \beta 1|-| 2 \mid-1$ and $\mathrm{p} \beta 1(-|2|-)$, corresponding to the sequences from the transcription initiation site to 91 nucleotides $3^{\prime}$ of the human $\beta$-globin polyadenylation signal, into HindIII- and $\mathrm{XbaI}$-digested pGEM2 vector DNA (Promega). Plasmid pHCL3, containing a full-length cDNA encoding hnRNP L (Piñol-Roma et al. 1989), was a generous gift from Dr. Maurice Swanson (University of Florida, Gainesville).

\section{Antisera and recombinant proteins}

Monoclonal antisera specific for hnRNP K (3C2 and 12G4) and hnRNP L (4D11) were prepared as described previously (PiñolRoma et al. 1988; Matunis et al. 1992) and were generous gifts from M. Michael (University of Pennsylvania School of Medicine, Philadelphia) and G. Dreyfuss. Recombinant hnRNP L was prepared by in vitro transcription/translation of plasmid pHCL3 in a rabbit reticulocyte lysate according to the manufacturer's instructions (Promega).

\section{RNA purification and S1 nuclease mapping analysis}

Nuclear and cytoplasmic RNAs were purified from monkey cells $48 \mathrm{hr}$ after transfection as described previously (Liu and Mertz 1993). The relative amounts of globin-like RNA accumulated in the nucleus and cytoplasm were determined by quantitative $S 1$ nuclease mapping techniques as described previously (Liu and Mertz 1993). The probes used in the S1 nuclease mapping analyses are shown in the figures. Cellular $\beta$-actin RNA, mapped concurrently, served as an internal control for recovery of the RNA samples and purity of the nuclear RNA (Yu et al. 1991; Liu and Mertz 1993). Southern blot analysis of the relative amount of DpnI-resistant, $\beta$-globin-encoding plasmid DNA present in each nuclear sample prior to treatment with DNase I was performed as described elsewhere (Ryu 1989; Liu and Mertz 1993); this analysis was used to assay for both (1) nuclear contamination of cytoplasmic nucleic acid, and (2) differences in transfection efficiency (data not shown). The Sl nucleaseprotected DNA fragments were electrophoresed in $5 \%$ polyacrylamide gels containing $8 \mathrm{M}$ urea. Quantitations were performed by scanning with a PhosphorImager (Molecular Dynamics).

\section{$R T-P C R$ and PCR}

Prior to reverse transcription, each RNA sample for RT-PCR analysis was treated with RNase-free, FPLC-pure DNase I (Pharmacia). Each reverse transcription reaction contained $2 \%$ of the cytoplasmic RNA harvested from a $100-\mathrm{mm}$ dish of transfected cells, 25 units of AMV reverse transcriptase (Boehringer-Mannheim), $25 \mathrm{ng}$ of $3^{\prime}$-antisense primer (5'-TTAGGCAGAATCC

AGATGCTCAAGGCC-3'), $1.25 \mathrm{~mm}$ of each of the four dNTPs, and 20 units of RNasin (Promega) in a total volume of $20 \mu \mathrm{l}$. After incubation at $42^{\circ} \mathrm{C}$ for $1.5 \mathrm{hr}$, the reaction mixture was incubated at $95^{\circ} \mathrm{C}$ for $10 \mathrm{~min}$ and quickly chilled on ice to denature the heteroduplexes. Afterward, the PCR reaction was performed in a $50-\mu$ l volume containing $10 \mathrm{mM}$ Tris- $\mathrm{HCl} / \mathrm{pH}$ 8.3), $1.5 \mathrm{mM} \mathrm{MgCl}_{2}, 50 \mathrm{mM} \mathrm{KCl}, 1.25 \mathrm{~mm}$ of each of the four dNTPs, 2.5 units of Taq polymerase, $1 \mu \mathrm{M}$ each of the 3 '-an- tisense primer and the $5^{\prime}$ primer $15^{\prime}$-ACATTTGCTTCTGACACAACTGTG-3'), and the $20 \mu \mathrm{l}$ from the reverse transcription reaction. A Perkin-Elmer Cetus thermal cycler was used with denaturation at $94^{\circ} \mathrm{C}$ for $1 \mathrm{~min}$, primer annealing at $55^{\circ} \mathrm{C}$ for 1 min, and extension at $72^{\circ} \mathrm{C}$ for $2 \mathrm{~min}$ for 35 cycles.

\section{UV-cross-linking assays}

The RNA substrates for the in vitro studies were synthesized using a commercial T7/SP6 in vitro transcription kit (Promega). The DNAs used as templates for the RNA syntheses were derivatives of pGEM5Z $1+$ ) (Promega). One microgram of each template was linearized by digestion with $\mathrm{NcoI}$ and transcribed with $\mathrm{T} 7 \mathrm{RNA}$ polymerase at $37^{\circ} \mathrm{C}$ for $1 \mathrm{hr}$ in the presence of either $\left[\alpha^{-32} \mathrm{P}\right] \mathrm{UTP}$ or $\left[\alpha^{-32} \mathrm{P}\right] \mathrm{CTP}$ (3000 Ci/mmole, Amersham). Wild-type and mutant RNA substrates were prepared in parallel to ensure that their specific activities were similar. After RNA synthesis, the DNA templates were degraded by incubation with RNase-free DNase I (Promega) for $15 \mathrm{~min}$ at $30^{\circ} \mathrm{C}$, and the full-length, radiolabeled transcripts were purified by polyacrylamide gel electrophoresis as described previously (Liu 1994). For UV-cross-linking assays, $5 \times 10^{4} \mathrm{cpm}$ of ${ }^{32} \mathrm{P}$-labeled RNA was incubated, together with 5-10 $\mu \mathrm{g}$ of HeLa or COS cell nuclear extract or with $1 \mu \mathrm{l}$ of rabbit reticulocyte lysate containing recombinant hnRNP L, in $15 \mathrm{~mm}$ HEPES (pH 7.9), $10 \mathrm{mM} \mathrm{KCl}$, $10 \%$ glycerol, $0.2 \mathrm{~mm}$ dithiothreitol, and $2 \mu \mathrm{g}$ of yeast tRNA (Boehringer Mannheim) in a total volume of $10 \mu \mathrm{l}$ at $30^{\circ} \mathrm{C}$ for 10 min (Gillis and Malter 1991). Afterward, the reaction mixture was irradiated in a UV-Stratalinker (Stratagene) for $10 \mathrm{~min}$ on the automatic setting. RNase A was added to a final concentration of $1 \mathrm{mg} / \mathrm{ml}$, and incubation was continued at $37^{\circ} \mathrm{C}$ for 15 min. After addition of SDS-PAGE sample buffer, each sample was incubated at $100^{\circ} \mathrm{C}$ for $4 \mathrm{~min}$ and electrophoresed in a $15 \%$ polyacrylamide gel containing $0.1 \%$ SDS. The gels were either dried and autoradiographed overnight at $-70^{\circ} \mathrm{C}$ or exposed to a Phosphorlmager screen and scanned in a PhosphorImager (Molecular Dynamics). Competition UV-cross-linking assays were performed similarly, except for preincubation of the nuclear extract or recombinant hnRNP L-containing reticulocyte lysate with unlabeled RNA prepared following the protocol of Gurevich et al. (1991).

\section{Immunoprecipitation assays}

Proteins bound to the radiolabeled RNAs were radiolabeled by cross-linking with UV light as described above. Afterward, immunoprecipitations were performed by first prebinding $2 \mu \mathrm{l}$ of monoclonal antibody or preimmune serum to $25 \mu \mathrm{l}$ of protein A-agarose beads (Boehringer Mannheim) by incubation for 60 min at $4^{\circ} \mathrm{C}$ in $10 \mathrm{~mm}$ Tris- $\mathrm{HCl}(\mathrm{pH} 7.4), 100 \mathrm{~mm} \mathrm{NaCl}, 2.5 \mathrm{~mm}$ $\mathrm{MgCl}_{2}, 0.5 \%$ Triton X-100, $1 \mu \mathrm{g} / \mathrm{ml}$ of leupeptin, $1 \mu \mathrm{g} / \mathrm{ml}$ of pepstatin, and $0.5 \%$ aprotinin. Because the $4 \mathrm{D} 11$ monoclonal antibody does not bind to protein A-agarose directly (PinolRoma et al. 1989), it was preincubated with rabbit anti-mouse IgG antiserum before incubation with the protein A-agarose beads. The antibody-bound beads were washed three times with the incubation buffer and resuspended in $500 \mu$ lof this buffer prior to addition of the cross-linked proteins. After incubation for $10 \mathrm{~min}$ at $4^{\circ} \mathrm{C}$, the beads were washed four times with incubation buffer to remove unbound proteins. The bound proteins were released from the beads by incubation at $95^{\circ} \mathrm{C}$ for 4 min in $2 \times$ SDS loading buffer and analyzed by $10 \%$ SDS-PAGE.

\section{Acknowledgments}

We thank Dana Willard, Xiang Fei, Nancy Zink, and Greg 
Gelembiuk for excellent technical assistance, Jim Malter for plasmid po19, Matthew Michael and Gideon Dreyfuss for antibody against hnRNP L, Maurice Swanson for plasmid pHCL3, Fengrong Zuo for COS cell nuclear extract, and Walter Hubert, Jim Malter, and Mike Terns for technical advice. We also thank Jim Dahlberg, Paul Lambert, Jeff Ross, Carl Baker, Mike Terns, and members of our laboratory for discussions and helpful comments on the manuscript. This work was supported by U.S. Public Health Service grants CA-07175 and CA-22443 from the National Institutes of Health.

The publication costs of this article were defrayed in part by payment of page charges. This article must therefore be hereby marked "advertisement" in accordance with 18 USC section 1734 solely to indicate this fact.

\section{References}

Bennett, M., R.S. Piñol-Roma, D. Staknis, G. Dreyfuss, and R. Reed. 1992. Differential binding of heterogeneous nuclear ribonucleoproteins to mRNA precursors prior to spliceosome assembly in vitro. Mol. Cell. Biol. 12: 3165-3175.

Bray, M., S. Prasad, J.W. Dubay, E. Hunter, K.T. Jeang, D. Rekosh, and M.L. Hammarskjold. 1994. A small element from the Mason-Pfizer monkey virus genome makes human immunodeficiency virus type 1 expression and replication Revindependent. Proc. Natl. Acad. Sci. 91: 1256-1260.

Brighty, D.W. and M. Rosenberg. 1994. A cis-acting repressive sequence that overlaps the Rev-responsive element of human immunodeficiency virus type l regulates nuclear retention of env mRNAs independently of known splice signals. Proc. Nat1. Acad. Sci. 91: 8314-8318.

Buchman, A.R. and P. Berg. 1988. Comparison of intron-dependent and intron-independent gene expression. Mol. Cell. Biol. 8: 4395-4405.

Burd, C.G. and G. Dreyfuss. 1994. RNA binding specificity of hnRNP Al: Significance of hnRNP A1 high-affinity binding sites in pre-mRNA splicing. EMBO I. 13: 1197-1204.

Callis, J., M. Fromm, and V. Walbot. 1987. Introns increase gene expression in cultured maize cells. Genes \& Dev. 1: 11831200.

Chang, D.D. and P.A. Sharp. 1989. Regulation by HIV Rev depends upon recognition of splice sites. Cell 59: 789-795.

Chiou, H.C., C. Dabrowski, and J.C. Alwine. 1991. Simian virus 40 late mRNA leader sequences involved in augmenting mRNA accumulation via multiple mechanisms, including increased polyadenylation efficiency. J. Virol. 65: 66776685.

Chung, S. and R.P. Perry. 1989. Importance of introns for expression of mouse ribosomal protein gene rpL32. Mol. Cell. Biol. 9: 2075-2082.

Collis, P., M. Antoniou, and F. Grosveld. 1990. Definition of the minimal requirements within the human beta-globin gene and the dominant control region for high level expression. EMBO I. 9: 233-240.

Cullen, B.R., J. Hauber, K. Campbell, J.G. Sodroski, W.A. Haseltine, and C.A. Rosen. 1988. Subcellular localization of the human immunodeficiency virus trans-acting art gene product. J. Virol. 62: 2498-2501.

Deng, T., Y. Li, and L.F. Johnson. 1989. Thymidylate synthase gene expression is stimulated by some (but not all) introns. Nucleic Acids Res. 17: 645-658.

Dignam, J.D., R.M. Lebovitz, and R.G. Roeder. 1983. Accurate transcription initiation by RNA polymerase II in a soluble extract from isolated mammalian nuclei. Nucleic Acids Res. 11: 1475-1489.
Dreyfuss, G., M.J. Matunis, R.S. Piñol-Roma, and C.G. Burd. 1993. hnRNP proteins and the biogenesis of mRNA. Annu. Rev. Biochem. 62: 289-321.

Eckner, R., W. Ellmeier, and M.L. Birnstiel. 1991. Mature mRNA 3 ' end formation stimulates RNA export from the nucleus. EMBO I. 10: 3513-3522.

Emerman, M., R. Vazeux, and K. Peden. 1989. The rev gene product of the human immunodeficiency virus affects envelope-specific RNA localization. Cell 57: 1155-1165.

Felber, B.K., M. Hadzopoulou-Cladaras, C. Cladaras, T. Copeland, and G.N. Pavlakis. 1989. Rev protein of human immunodeficiency virus type 1 affects the stability and transport of the viral mRNA. Proc. Natl. Acad. Sci. 86: 1495-1499.

Garcia-Blanco, M.A., S. Jamison, and P.A. Sharp. 1989. Identification and purification of a 62,000 dalton protein that binds specifically to a polypyrimidine tract of introns. Genes \& Dev. 3: 1874-1886.

Gasser, C.S., C.C. Simonsen, J.W. Schilling, and R.T. Schimke. 1982. Expression of abbreviated mouse dihydrofolate reductase genes in cultured hamster cells. Proc. Natl. Acad. Sci. 79: $6522-6526$.

Ghetti, A., R.S. Piñol-Roma, W.M. Michael, C. Morandi, and G. Dreyfuss. 1992. hnRNP I, the polypyrimidine tract-binding protein: distinct nuclear localization and association with hnRNAs. Nucleic Acids Res. 20: 3671-3678.

Gillis, P. and J.S. Malter. 1991. The adenosine-uridine binding factor recognizes the AU-rich elements of cytokine, lymphokine, and oncogene mRNAs. J. Biol. Chem. 266: 31723177.

Good, P.J., R.C. Welch, W.S. Ryu, and J.E. Mertz. 1988. The late spliced 19S and 16S RNAs of simian virus 40 can be synthesized from a common pool of transcripts. J. Virol. 62: 563571.

Green, M.R. 1991. Biochemical mechanisms of constitutive and regulated pre-mRNA splicing. Annu. Rev. Cell Biol. 7: 559599.

Greenspan, D.S. and S.M. Weissman. 1985. Synthesis of predominantly unspliced cytoplasmic RNAs by chimeric herpes simplex virus type 1 thymidine kinase-human ß-globin genes. Mol. Cell. Biol. 5: 1894-1900.

Gross, M.K., M.S. Kainz, and G.F. Merrill. 1987. Introns are inconsequential to efficient formation of cellular thymidine kinase mRNA in mouse L cells. Mol. Cell. Biol. 7: 45764581.

Gruss, P., C.J. Lai, R. Dhar, and G. Khoury. 1979. Splicing as a requirement for biogenesis of functional 16S mRNA of simian virus 40. Proc. Natl. Acad. Sci. 76: 4317-4321.

Gurevich, V.V., I.D. Pokrovskaya, T.A. Obukhova, and S.A. Zozulya. 1991. Preparative in vitro mRNA synthesis using SP6 and T7 RNA polymerases. Anal. Biochem. 195: 207-213.

Hadzopoulou-Cladaras, M.B., B.K. Felber, C. Cladaras, A. Athanassopoulos, A. Tse, and G.N. Pavlakis. 1989. The rev (trs/ art) protein of human immunodeficiency virus type $l$ affects viral $\mathrm{mRNA}$ and protein expression via a cis-acting sequence in the env region. $J$. Virol. 63: $1265-1274$.

Hamer, D.H. and P. Leder. 1979. SV40 recombinants carrying a functional RNA splice junction and polyadenylation site from the chromosomal mouse beta maj globin gene. Cell 17: 737-747.

Hammarskjold, M.L., J. Heimer, B. Hammarskjold, I. Sangwan, L. Albert, and D. Rekosh. 1989. Regulation of human immunodeficiency virus env expression by the rev gene product. $J$. Virol. 63: 1959-1966.

Hattori, K., P. Angel, M.M. Le Beau, and M. Karin. 1988. Structure and chromosomal localization of the functional intronless human JUN protooncogene. Proc. Natl. Acad. Sci. 
85: $9148-9152$.

Huang, J. and T.J. Liang. 1993. A novel hepatitis B virus (HBV) genetic element with Rev response element-like properties that is essential for expression of $\mathrm{HBV}$ gene products. Mol. Cell. Biol. 13: 7476-7486.

Huang, M.T. and C.M. Gorman. 1990. Intervening sequences increase efficiency of RNA 3' processing and accumulation of cytoplasmic RNA. Nucleic Acids Res. 18: 937-947.

Huang, Z.M. and T.S. Yen. 1994. Hepatitis B virus RNA element that facilitates accumulation of surface gene transcripts in the cytoplasm. I. Virol. 68: 3193-3199.

Jonsson, J.J., M.D. Foresman, N. Wilson, and R.S. Mclvor. 1992. Intron requirement for expression of the human purine nucleoside phosphorylase gene. Nucleic Acids Res. 20: 31913198.

Kedes, L.H. 1979. Histone genes and histone messengers. Annu. Rev. Biochem. 48: 837-870.

Koilka, B.K., T. Frielle, S. Collins, T. Yang-Feng, T.S. Kobilka, U. Francke, R.J. Lefkowitz, and M.G. Caron. 1987. An intronless gene encoding a potential member of the family of receptors coupled to guanine nucleotide regulatory proteins. Nature 329: 75-79.

Lang, K.M., V. van Santen, and R.A. Spritz. 1985. The two intervening sequences of human beta- and gamma-globin premRNAs are excised in a preferred temporal order in vitro. EMBO I. 4: 1991-1996.

Legrain, P. and M. Rosbash. 1989. Some cis- and trans-acting mutants for splicing target pre-mRNA to the cytoplasm. Cell 57: 573-583.

Liu, X. 1994. "Effects of intron and exon sequence elements on intron-dependent and intron-independent gene expression." Ph.D. thesis, University of Wisconsin-Madison, Madison, WI.

Liu, X. and J.E. Mertz. 1993. Polyadenylation site selection cannot occur in vivo after excision of the 3 '-terminal intron. Nucleic Acids Res. 21: 5256-5263.

Lu, X.B., J. Heimer, D. Rekosh, and M.L. Hammarskjold. 1990. U1 small nuclear RNA plays a direct role in the formation of a rev-regulated human immunodeficiency virus env mRNA that remains unspliced. Proc. Natl. Acad. Sci. 87: 75987602.

Malim, M.H. and B.R. Cullen. 1993. Rev and the fate of premRNA in the nucleus: implications for the regulation of RNA processing in eukaryotes. Mol. Cell. Biol. 13: 61806189.

Malim, M.H., J. Hauber, S.Y. Le, J.V. Maizel, and B.R. Cullen. 1989. The HIV-1 rev trans-activator acts through a structured target sequence to activate nuclear export of unspliced viral mRNA. Nature 338: 254-257.

Matunis, E.L., M.J. Matunis, and G. Dreyfuss. 1993. Association of individual hnRNP proteins and snRNPs with nascent transcripts. I. Cell. Biol. 121: 219-228.

Matunis, M.J., W.M. Michael, and G. Dreyfuss. 1992. Characterization and primary structure of the poly(C)-binding heterogeneous nuclear ribonucleoprotein complex $\mathrm{K}$ protein. Mol. Cell. Biol. 12: 164-171.

McKnight, S.L. 1980. The nucleotide sequence and transcript map of the herpes simplex virus thymidine kinase gene. $\mathrm{Nu}$ cleic Acids Res. 8: 5949-5964.

McKnight, S., E.R. Gavis, R. Kingsbury, and R. Axel. 1981. Analysis of transcriptional regulatory signals of the HSV thymidine kinase gene: identification of an upstream control region. Cell 25: 385-398.

Nagata, S., N. Mantei, and C. Weissmann. 1980. The structure of one of the eight or more distinct chromosomal genes for human interferon- $\alpha$. Nature 287: 401-408.
Nesic, D., J. Cheng, and L.E. Maquat. 1993. Sequences within the last intron function in RNA 3 '-end formation in cultured cells. Mol. Cell. Biol. 13: 3359-3369.

Nesic, D. and L.E. Maquat. 1994. Upstream introns influence the efficiency of final intron removal and RNA $3^{\prime}$-end formation. Genes \& Dev. 8: 363-375.

Neuberger, M.S. and G.T. Williams. 1988. The intron requirement for immunoglobulin gene expression is dependent upon the promoter. Nucleic Acids Res. 16: 6713-6724.

Niwa, M. and S.M. Berget. 1991. Mutation of the AAUAAA polyadenylation signal depresses in vitro splicing of proximal but not distal introns. Genes \& Dev. 5: 2086-2095.

Niwa, M., S.D. Rose, and S.M. Berget. 1990. In vitro polyadenylation is stimulated by the presence of an upstream intron. Genes \& Dev. 4: 1552-1559.

Pandey, N.B., N. Chodchoy, T.J. Liu, and W.F. Marzluff. 1990. Introns in histone genes alter the distribution of $3^{\prime}$ ends. Nucleic Acids Res. 18: 3161-3170.

Patton, J.G., S.A. Mayer, P. Tempst, and G.B. Nadal. 1991. Characterization and molecular cloning of polypyrimidine tractbinding protein: a component of a complex necessary for pre-mRNA splicing. Genes \& Dev. 5: 1237-1251.

Piñol-Roma, S., Y.D. Choi, M.J. Matunis, and G. Dreyfuss. 1988. Immunopurification of heterogeneous nuclear ribonucleoprotein particles reveals an assortment of RNA-binding proteins. Genes \& Dev. 2: 215-227.

Pinol-Roma, S. and G. Dreyfuss. 1992. Shuttling of pre-mRNA binding proteins between nucleus and cytoplasm. Nature 355: 730-732.

Piñol-Roma, S., M. Swanson, J. Gall, and G. Dreyfuss. 1989. A novel heterogeneous nuclear RNP protein with a unique distribution on nascent transcripts. /. Cell. Biol. 109: 25752587.

Rosen, C.A., E. Terwilliger, A. Dayton, J.G. Sodroski, and W.A. Haseltine. 1988. Intragenic cis-acting art gene-responsive sequences of the human immunodeficiency virus. Proc. Natl. Acad. Sci. 85: 2071-2075.

Ryu, W.-S. 1989. "Processing of transcripts made from introncontaining and intronless protein-coding genes." $\mathrm{Ph} . \mathrm{D}$. thesis, University of Wisconsin-Madison, Madison, WI.

Ryu, W.-S. and J.E. Mertz. 1989. Simian virus 40 late transcripts lacking excisable intervening sequences are defective in both stability in the nucleus and transport to the cytoplasm. I. Virol. 63: 4386-4394.

Sambrook, J., E.F. Fritsch, and T. Maniatis. 1989. Molecular cloning: A laboratory manual, 2nd ed. Cold Spring Harbor Laboratory Press, Cold Spring Harbor, New York.

Swanson, M.S. and G. Dreyfuss. 1988. Classification and purification of proteins of heterogeneous nuclear ribonucleoprotein particles by RNA-binding specificities. Mol. Cell. Biol. 8: $2237-2241$.

Treisman, R., U. Novak, J. Favaloro, and R. Kamen. 1981. Transformation of rat cells by an altered polyoma virus genome expressing only the middle-T protein. Nature 292: 595-600.

Yu, X.-M., G.W. Gelembiuk, C.-Y. Wang, W.-S. Ryu, and J.E. Mertz. 1991. Expression from herpes virus promoters does not relieve the intron requirement for cytoplasmic accumulation of human beta-globin mRNA. Nucleic Acids Res. 19: $7231-7234$. 


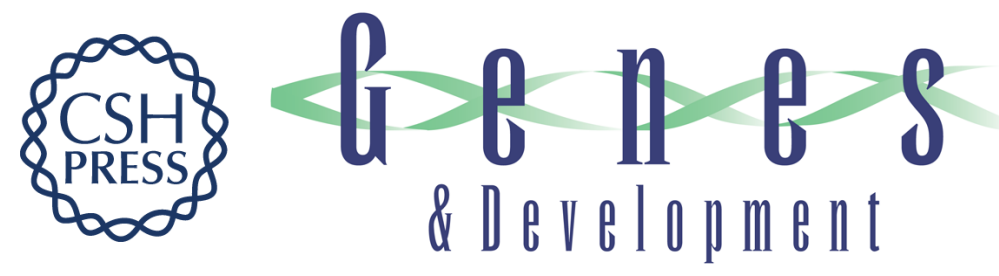

\section{HnRNP L binds a cis-acting RNA sequence element that enables intron-dependent gene expression.}

$X$ Liu and J E Mertz

Genes Dev. 1995, 9:

Access the most recent version at doi:10.1101/gad.9.14.1766

References This article cites 63 articles, 35 of which can be accessed free at:

http://genesdev.cshlp.org/content/9/14/1766.full.html\#ref-list-1

License

Email Alerting

Service

Receive free email alerts when new articles cite this article - sign up in the box at the top right corner of the article or click here.

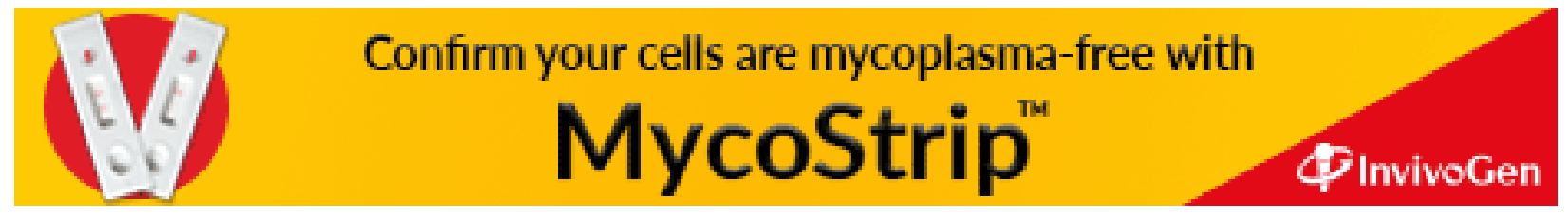

